\title{
Rotor Voltage Dynamics in the Doubly Fed Induction Generator During Grid Faults
}

\author{
Francisco K. A. Lima, Alvaro Luna, Student Member, IEEE, Pedro Rodriguez, Member, IEEE, \\ Edson H. Watanabe, Senior Member, IEEE, and Frede Blaabjerg, Fellow, IEEE
}

\begin{abstract}
This paper presents a new control strategy for the rotor-side converter (RSC) of wind turbines (WTs) based on doubly fed induction generators (DFIG) that intends to improve its low-voltage ride through capability. The main objective of this work is to design an algorithm that would enable the system to control the initial overcurrents that appear in the generator during voltage sags, which can damage the RSC, without tripping it. As a difference with classical solutions, based on the installation of crowbar circuits, this operation mode permits to keep the inverter connected to the generator, something that would permit the injection of power to the grid during the fault, as the new grid codes demand. A theoretical study of the dynamical behavior of the rotor voltage is also developed, in order to show that the voltage at the rotor terminals required for the control strategy implementation remains under controllable limits. In order to validate the proposed control system simulation, results have been collected using PSCAD/EMTDC and experimental tests have been carried out in a scaled prototype.
\end{abstract}

Index Terms-AC generators, current control, electric variables control, power system faults, wind power generation.

\section{INTRODUCTION}

$\mathbf{T}$ HE INCREASING capacity of the installed wind power generation facilities linked to the electrical network, as well as the high-scale penetration of such systems in the next future, has made it necessary to redesign the existing grid code (GC) requirements, which now include specific requirements regarding the operation of wind power generators and farms [1], [2] under generic situations. Between these new demands, those that concern the capability of wind power generators to remain connected to the grid, in case of grid voltage sags, have gained lately a great importance [3]-[6].

At the present time, all the existing GCs include fault ridethrough requirements for wind turbines (WTs). These standards determine the fault boundaries among the ones a grid connected WT shall remain connected to the network, giving rise to spe-

Manuscript received November 8, 2008; revised April 18, 2009. Current version published January 29, 2010. This work was supported in part by the CNPq under Grant 473294/2004-4 and Grant 141079/2005-3, in part by FAPERJ, and in part by the Ministerio de Ciencia y Tecnologia of Spain under the project ENE2008-06588-C04-03/ALT. Recommended for publication by Associate Editor B. Wu.

F. K. A. Lima and E. H. Watanabe are with the COPPE, Federal University of Rio de Janeiro, Rio de Janeiro 21941-972, Brazil (e-mail: kleber@coe.ufrj.br; watanabe@coe.ufrj.br).

A. Luna and P. Rodriguez are with the Department of Electrical Engineering, Universitat Politecnica de Catalunya, Barcelona 08222, Spain (e-mail: luna@ee.upc.edu; prodriguez@ee.upc.edu).

F. Blaabjerg is with the Faculty of Engineering, Science and Medicine, Aalborg University, Aalborg 9220, Denmark (e-mail: fbl@iet.aau.dk).

Color versions of one or more of the figures in this paper are available online at http://ieeexplore.ieee.org.

Digital Object Identifier 10.1109/TPEL.2009.2025651

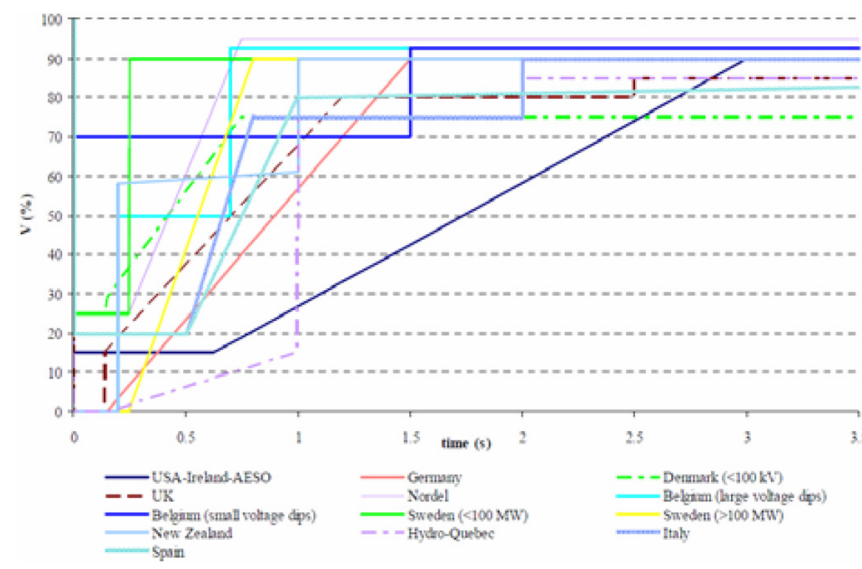

Fig. 1. Comparison of different LVRT requirements for three-phase balanced faults.

cific voltage profiles that specify the depth and clearance time of the voltage sags that WTs must withstand without tripping. Such requirements are known as fault ride through (FRT) or low-voltage ride through (LVRT) and they are described by a voltage versus time characteristic, denoting the minimum required immunity of the wind power station.

In Fig. 1, the LVRT requirements cited in different GCs [3]-[7] for three-phase faults at HV level are presented together. As it can be understood from the figure, there is a lack of standardization among the different transmission system operators, as the FRT requirements depend highly on the specific characteristics of the power systems in each country.

The LVRT capability is of special interest in wind power systems based on doubly fed induction generators (DFIGs). In this sort of machine, the voltage drop in the stator windings, suffered during a voltage dip, produces a sudden change in the stator flux of the DFIG [7]. As a consequence of this transient the currents in the stator increases rapidly, experiencing an overcurrent that is transmitted, due to the magnetic coupling, to the rotor windings. These overcurrents, which can be up to three times the nominal value of the current [8], can damage the rotor and stator windings, but its consequences can be especially critical for the semiconductors of the rotor-side converter (RSC), that can reach a thermal breakdown.

Nevertheless, and although this kind of facilities are very sensitive to voltage faults, DFIG-based WTs are responsible of producing the $50 \%$ of the installed wind power worldwide [9]. Therefore, improving its behavior in faulty scenarios, in order to fulfill the new LVRT requirements, has become an issue of great interest for WT manufacturers. 


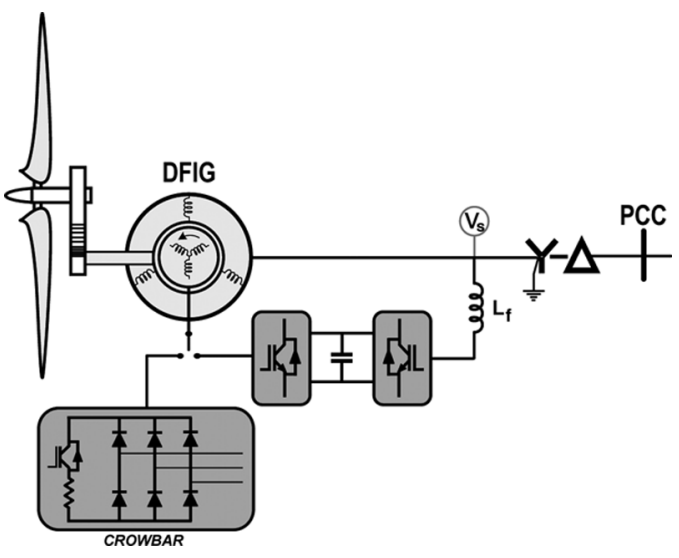

Fig. 2. Operation of a grid connected DFIG-WT controlled by means of a back-to-back power converter.

Within this field several studies have been carried out in order to improve the FRT capability of WTs [10]-[30]. Among the different solutions, the most extended one is based on the use of a protective circuit known as crowbar. This device consists of a bank of resistors, which are connected to the rotor windings by means of controllable switches [31]-[36]. When a fault occurs, the rotor windings get connected to the resistors while the converter is tripped. Thus, the short-circuit current flows through this crowbar instead of the rotor-side inverter. In Fig. 2, the block diagram of a DFIG WT equipped with such circuit is shown.

Although crowbar circuits are able to protect the machine and the converter during the fault, its usage implies the installation of extra hardware in the system, something that finally increases the costs and hinders its reliability. Moreover, and despite the fact that a crowbar is able to reduce the current peaks, this device does not avoid the disconnection of the RSC after the fault is detected, something that disables the control of active and reactive power to the grid in such conditions. This last issue is of great importance in the present GCs that demand a certain delivery of active and reactive power during the fault [37].

Regarding this drawback some authors have proposed new solutions for reducing the overcurrents in the rotor in faulty scenarios, by means of designing specific control algorithms for the RSC that would permit to avoid its disconnection, improving thus the controllability of the system. However, some of these algorithms turn out to be complicated and depend strongly on the estimation of certain parameters, what finally play against its robustness. This is the case of Xiang et al. [10] who present a solution based on counteracting the negative and zero sequence of the stator's flux during the fault by means of injecting the appropriate current through the rotor windings.

The aim of this paper is to propose a new control strategy for the RSC that would permit reducing the overcurrents in the generator's windings under fault conditions without tripping the converter. As a difference with previous solutions, the proposed control system is based on a simple concept that is to feedback the measured currents in the stator as the set point for the current controller of the RSC.

In the following, the performance of this strategy will be studied analytically and tested through simulations based on

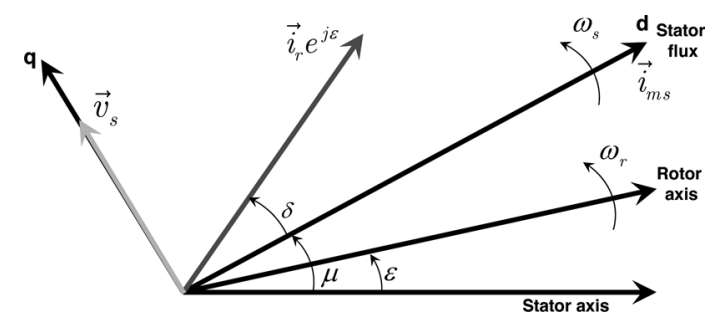

Fig. 3. Vectorial diagram in the $d q$ reference frame considering a FOC philosophy.

PSCAD/EMTDC and also by means of experimental results obtained in a scaled workbench. This work will be not only focused on the response of the current control but also on the estimation of the rotor voltage that is needed to inject the desired current. This study will present as a novel contribution, an analytical expression for determining the maximum voltage at the rotor windings, in function of the fault conditions, that can be found using this strategy, permitting thus to dimension the RSC depending on the desired FRT capabilities of the system.

\section{SIMPLIFIEd MODELING OF THE DFIG}

This section will be devoted to the modeling of the DFIG. The objective of this part will be focused on finding a simple relationship between the state space variables that could permit to predict the behavior of DFIG under fault conditions. Later this analysis will constitute the basis for the design of the control system for the RSC.

\section{A. Reference Frame System}

In this paper, the rotor-side controller has been implemented considering a field-oriented control (FOC) philosophy in the $d q$ reference frame [38]. In this kind of systems, the $d q$-axes are aligned with the stator flux, as it can be noticed from Fig. 3. This reference frame, known as synchronous reference frame (SRF), is useful in order to reduce partially the complexity of the mathematical equations that describe the system.

As it can be deducted from Fig. 3, due to the low stator resistance, the voltage of the stator $v_{\mathrm{s}}$ can be considered to be $90^{\circ}$ leaded with respect to the stator flux, and hence almost completely aligned with the in-quadrature axis, $q$, while the magnetizing current in the stator has a single component in the $d$-axis.

\section{B. Simplified Modeling for the DFIG}

The voltage and magnetic flux of the stator in a fourth-order model can be written as

$$
\begin{aligned}
& v_{\mathrm{ds}}=R_{\mathrm{s}} i_{\mathrm{ds}}+\frac{d \lambda_{\mathrm{ds}}}{d t}-\omega_{\mathrm{s}} \lambda_{\mathrm{qs}} \\
& v_{\mathrm{qs}}=R_{\mathrm{s}} i_{\mathrm{qs}}+\frac{d \lambda_{\mathrm{qs}}}{d t}+\omega_{\mathrm{s}} \lambda_{\mathrm{ds}} \\
& \lambda_{\mathrm{ds}}=L_{\mathrm{s}} i_{\mathrm{ds}}+L_{\mathrm{m}} i_{\mathrm{dr}} \\
& \lambda_{\mathrm{qs}}=L_{\mathrm{s}} i_{\mathrm{qs}}+L_{\mathrm{m}} i_{\mathrm{qr}} .
\end{aligned}
$$


In an analogous way, the equations that describe the dynamics of the voltage and magnetic flux at the rotor are

$$
\begin{aligned}
& v_{\mathrm{dr}}=R_{\mathrm{r}} i_{\mathrm{dr}}+\frac{d \lambda_{\mathrm{dr}}}{d t}-\omega_{\mathrm{slip}} \lambda_{\mathrm{qr}} \\
& v_{\mathrm{qr}}=R_{\mathrm{r}} i_{\mathrm{qr}}+\frac{d \lambda_{\mathrm{qr}}}{d t}+\omega_{\mathrm{slip}} \lambda_{\mathrm{dr}} \\
& \lambda_{\mathrm{dr}}=L_{\mathrm{r}} i_{\mathrm{dr}}+L_{\mathrm{m}} i_{\mathrm{ds}} \\
& \lambda_{\mathrm{qr}}=L_{\mathrm{r}} i_{\mathrm{qr}}+L_{\mathrm{m}} i_{\mathrm{qs}}
\end{aligned}
$$

where $\lambda_{\mathrm{s}}$ and $\lambda_{\mathrm{r}}$ are the stator and rotor magnetic flux; $L_{\mathrm{S}}, L_{\mathrm{r}}$, and $L_{\mathrm{m}}$ are the stator, rotor, and magnetizing inductances; $v_{\mathrm{s}}$ and $i_{\mathrm{S}}$ are the stator voltages and currents; $v_{\mathrm{r}}$ and $i_{\mathrm{r}}$ are the rotor voltages and currents; $R_{\mathrm{r}}$ and $R_{\mathrm{s}}$ are the rotor and stator resistances; $\omega_{\mathrm{s}}$ and $\omega_{\mathrm{r}}$ are the synchronous and rotating angular frequencies, respectively, and $\omega_{\text {slip }}$ is the slip frequency.

Considering that the system described by (1) and (2) is linear, assuming that the magnetic circuit of the DFIG is linear, and later applying the Laplace transform, it is possible to obtain the following stator currents in the SRF [39]:

$$
\begin{aligned}
i_{\mathrm{ds}}= & \frac{\left(L_{\mathrm{s}} s+R_{\mathrm{s}}\right) v_{\mathrm{ds}}+\omega_{\mathrm{s}} L_{\mathrm{s}} v_{\mathrm{qs}}}{\left(L_{\mathrm{s}}^{2} s^{2}+2 L_{\mathrm{s}} R_{\mathrm{s}} s+R_{\mathrm{s}}^{2}+\omega_{\mathrm{s}}^{2} L_{\mathrm{s}}^{2}\right)} \\
& -\frac{\left(L_{\mathrm{s}} s^{2}+R_{\mathrm{s}} s+\omega_{\mathrm{s}}^{2} L_{\mathrm{s}}\right) L_{\mathrm{m}} i_{\mathrm{dr}}-R_{\mathrm{s}} \omega_{\mathrm{s}} L_{\mathrm{m}} i_{\mathrm{qr}}}{\left(L_{\mathrm{s}}^{2} s^{2}+2 L_{\mathrm{s}} R_{\mathrm{s}} s+R_{\mathrm{s}}^{2}+\omega_{\mathrm{s}}^{2} L_{\mathrm{s}}^{2}\right)} \\
i_{\mathrm{qs}}= & \frac{-\omega_{\mathrm{s}} L_{\mathrm{s}} v_{\mathrm{ds}}+\left(L_{\mathrm{s}} s+R_{\mathrm{s}}\right) v_{\mathrm{qs}}}{\left(L_{\mathrm{s}}^{2} s^{2}+2 L_{\mathrm{s}} R_{\mathrm{s}} s+R_{\mathrm{s}}^{2}+\omega_{\mathrm{s}}^{2} L_{\mathrm{s}}^{2}\right)} \\
& -\frac{R_{\mathrm{s}} \omega_{\mathrm{s}} L_{\mathrm{m}} i_{\mathrm{dr}}+\left(L_{\mathrm{s}} s^{2}+R_{\mathrm{s}} s+\omega_{\mathrm{s}}^{2} L_{\mathrm{s}}\right) L_{\mathrm{m}} i_{\mathrm{qr}}}{\left(L_{\mathrm{s}}^{2} s^{2}+2 L_{\mathrm{s}} R_{\mathrm{s}} s+R_{\mathrm{s}}^{2}+\omega_{\mathrm{s}}^{2} L_{\mathrm{s}}^{2}\right)} .
\end{aligned}
$$

Equations (3) and (4) can be simplified considering that the stator resistance is very low; thus, $R_{\mathrm{s}}^{2} \rightarrow 0$. In addition, and considering that in a FOC system the stator flux is aligned with the $d$-axis of the $d q \mathrm{SRF}$, its quadrature component, $\lambda_{\mathrm{qs}}$, is null. Besides, and assuming that the leakage inductance value is low, the stator voltage vector can be considered to be almost aligned with the in-quadrature axis, and hence the $v_{\mathrm{ds}}$ component can be neglected as well. In this manner, the previous equations can be rewritten as

$$
\begin{aligned}
i_{\mathrm{ds}}= & \frac{\omega_{\mathrm{s}} L_{\mathrm{s}} v_{\mathrm{qs}}}{\left(L_{\mathrm{s}} s^{2}+2 R_{\mathrm{s}} s+\omega_{\mathrm{s}}^{2} L_{\mathrm{s}}\right) L_{\mathrm{s}}} \\
& -\frac{\left(L_{\mathrm{s}} s^{2}+R_{\mathrm{s}} s+\omega_{\mathrm{s}}^{2} L_{\mathrm{s}}\right) L_{\mathrm{m}} i_{\mathrm{dr}}-R_{\mathrm{s}} \omega_{\mathrm{s}} L_{\mathrm{m}} i_{\mathrm{qr}}}{\left(L_{\mathrm{s}} s^{2}+2 R_{\mathrm{s}} s+\omega_{\mathrm{s}}^{2} L_{\mathrm{s}}\right) L_{\mathrm{s}}} \\
i_{\mathrm{qs}}= & \frac{\left(L_{\mathrm{s}} s+R_{\mathrm{s}}\right) v_{\mathrm{qs}}}{\left(L_{\mathrm{s}} s^{2}+2 R_{\mathrm{s}} s+\omega_{\mathrm{s}}^{2} L_{\mathrm{s}}\right) L_{\mathrm{s}}} \\
& -\frac{R_{\mathrm{s}} \omega_{\mathrm{s}} L_{\mathrm{m}} i_{\mathrm{dr}}+\left(L_{\mathrm{s}} s^{2}+R_{\mathrm{s}} s+\omega_{\mathrm{s}}^{2} L_{\mathrm{s}}\right) L_{\mathrm{m}} i_{\mathrm{qr}}}{\left(L_{\mathrm{s}} s^{2}+2 R_{\mathrm{s}} s+\omega_{\mathrm{s}}^{2} L_{\mathrm{s}}\right) L_{\mathrm{s}}} .
\end{aligned}
$$

Equations (5) and (6) can be simplified further. Taking into account that in the second term of both expressions, the crossed terms of the rotor current $i_{\mathrm{dr}}$ and $i_{\mathrm{qr}}$ are negligible, due to the low value of the $R_{\mathrm{S}} \omega_{\mathrm{s}} L_{\mathrm{m}}$ coefficient, and considering that the quotient shown in the following equation is almost equal to 1:

$$
\frac{\left(L_{\mathrm{s}} s^{2}+R_{\mathrm{S}} s+\omega_{\mathrm{S}}^{2} L_{\mathrm{s}}\right)}{\left(L_{\mathrm{S}} s^{2}+2 R_{\mathrm{S}} s+\omega_{\mathrm{S}}^{2} L_{\mathrm{S}}\right)} \cong 1
$$

the final simplified model can be obtained as detailed in the following:

$$
\begin{aligned}
& i_{\mathrm{ds}}=\frac{1}{L_{\mathrm{s}}} \frac{\omega_{\mathrm{s}}}{s^{2}+2\left(R_{\mathrm{s}} / L_{\mathrm{s}}\right) s+\omega_{\mathrm{s}}^{2}} v_{\mathrm{qs}}-\frac{L_{\mathrm{m}}}{L_{\mathrm{s}}} i_{\mathrm{dr}} \\
& i_{\mathrm{qs}}=\frac{1}{L_{\mathrm{s}}} \frac{s+R_{\mathrm{s}} / L_{\mathrm{s}}}{s^{2}+2\left(R_{\mathrm{s}} / L_{\mathrm{s}}\right) s+\omega_{\mathrm{s}}^{2}} v_{\mathrm{qs}}-\frac{L_{\mathrm{m}}}{L_{\mathrm{s}}} i_{\mathrm{qr}} .
\end{aligned}
$$

In both equations, the rotor current and the stator voltage appear as the input variables, as the first one is fixed by the RSC while $v_{\mathrm{qs}}$ depends on the grid behavior.

As it can be deducted from (8) and (9), any variation in the stator voltage introduce oscillations in the $d q$ components of the stator currents in the SRF. The frequency of such oscillation is equal to the grid frequency and its damping is very poor, due to the low value of the stator resistance $R_{\mathrm{S}}$ (generally around 0.005 p.u.).

This phenomenon can be specially noticed during voltage sags. If there is a balanced sag, the stator currents in $d q$ oscillate at $\omega_{\mathrm{s}}$, on the contrary, if the sag is unbalanced the negative sequence components that appear forces oscillations with a frequency equal to $2 \omega_{\mathrm{s}}$ in $v_{\mathrm{ds}}$ and $v_{\mathrm{qs}}$ that shall be added to the $\omega_{\mathrm{s}}$ ones that are generated by the sudden change in the positive sequence magnitude.

The steady-state equation of the simplified model described in (8) and (9) are written as

$$
\begin{aligned}
& i_{\mathrm{ds}}=\frac{1}{L_{\mathrm{s}} \omega_{\mathrm{s}}} v_{\mathrm{qs}}-\frac{L_{\mathrm{m}}}{L_{\mathrm{s}}} i_{\mathrm{dr}} \\
& i_{\mathrm{qs}}=\frac{R_{\mathrm{s}}}{L_{\mathrm{s}}^{2} \omega_{\mathrm{s}}^{2}} v_{\mathrm{qs}}-\frac{L_{\mathrm{m}}}{L_{\mathrm{s}}} i_{\mathrm{qr}} .
\end{aligned}
$$

By means of analyzing (11), it can be concluded that the multiplicative factor of the in-quadrature component of the stator's voltage tends to zero. Thus, and considering that $R_{\mathrm{S}} \ll L_{\mathrm{S}}^{2} \omega_{\mathrm{S}}^{2}$, this equation can be reduced to

$$
i_{\mathrm{qs}}=-\frac{L_{\mathrm{m}}}{L_{\mathrm{s}}} i_{\mathrm{qr}} .
$$

In (12), $i_{\mathrm{qs}}$ reveals the linear dependence between the stator and rotor current components on the in-quadrature axis.

On the other hand, the final value of $i_{\mathrm{ds}}$ in (10) depends upon two terms. The first one, considering the steady-state conditions, describes its relationship with the magnetizing current, while the second depends on the rotor's direct current component.

\section{Reliability of the Presented Model}

In this section, the simplified DFIG model presented in (8) and (9) is validated through simulations carried out in PSCAD/EMTDC. The simulation results, depicted in Fig. 4(a) and (b), show the response of the stator and rotor currents in the $d q$ axes when a $70 \%$ depth balanced voltage sag at the point of common coupling (PCC) occurs at $t=2 \mathrm{~s}$ and last after $200 \mathrm{~ms}$. 


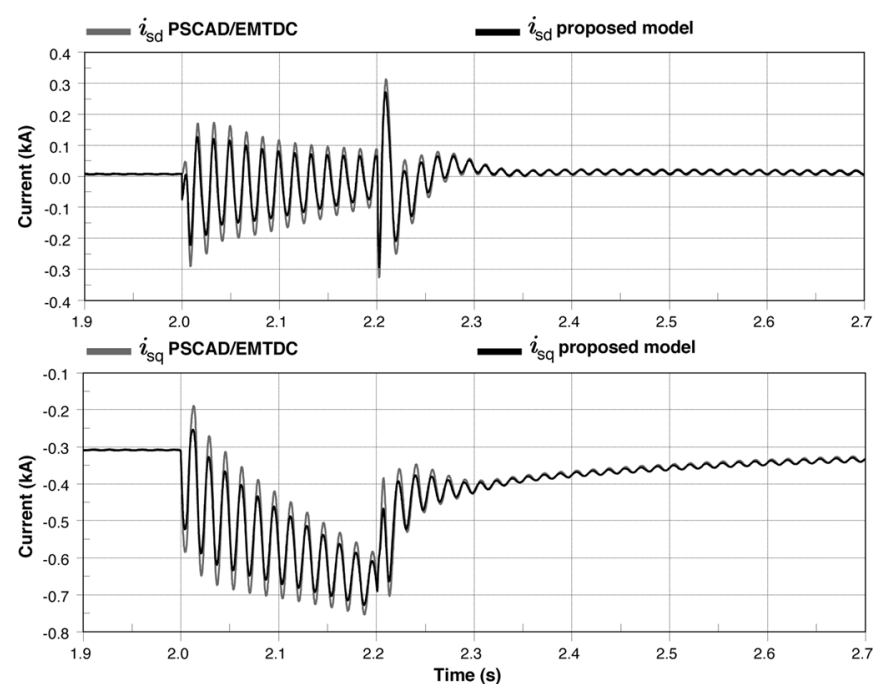

(a)

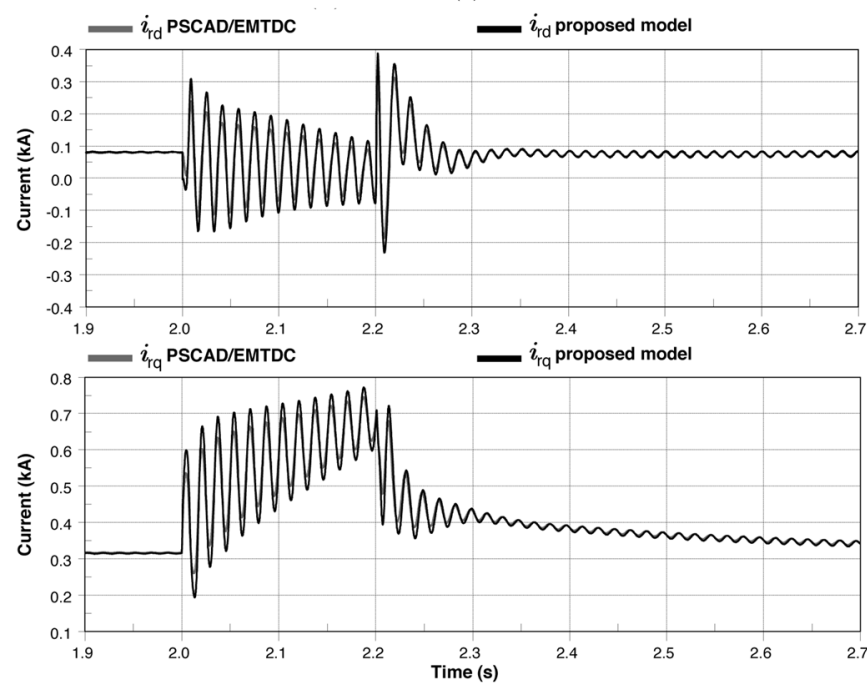

(b)

Fig. 4. Transient response of the stator and rotor currents with the proposed simplified model in front of the traditional fourth-order model, when a $70 \%$ depth three-phase balanced fault is applied at $t=2.0 \mathrm{~s}$ and cleared after $200 \mathrm{~ms}$. (a) Stator currents. (b) Rotor currents.

In both figures, the output of a classical fourth-order model is also shown in the same graph, in order to prove the accuracy of the proposed simplified model. As it can be easily realized, these results permit to conclude that the proposed simplified model describes the DFIG's behavior accurately.

In this point, it is worth to mention that the current waveforms in Fig. 4(a) and (b) show clearly the current peaks that appear in the rotor and in the stator windings when the fault occurs, as well as when it is cleared. Although its magnitude depends upon other parameters, the simulations show peaks that exceed two times the rated current of the rotor side converter, something that would damage seriously this device in a real wind power plant.

In order to protect the power converter under such conditions, the installation of crowbar circuits have been broadly used. In these applications, there are two main requirements that give an
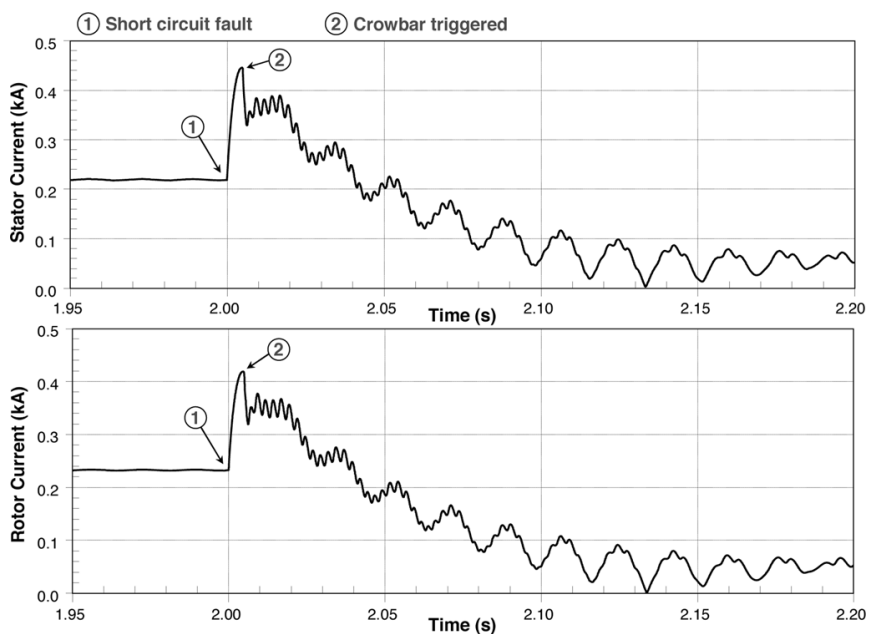

Fig. 5. Rotor and stator currents during a voltage sag when a crowbar circuit is used. In this case, the sag appears at $t=2.0 \mathrm{~s}$ and last after $300 \mathrm{~ms}$, and the crowbar is connected at $2.005 \mathrm{~s}$.

upper and a lower limit to the crowbar resistance. The resistance should be high to limit the short-circuit current, but at the same time, it should be low enough to avoid a too $\mathrm{HV}$ in the rotor circuit [34].

In Fig. 5, the typical behavior of the stator and rotor currents, considering its aggregate value $i_{\Sigma}=\sqrt{i_{a}^{2}+i_{b}^{2}+i_{c}^{2}}$ under fault conditions when using a crowbar circuit, is shown. The dynamics of the system stands out clearly the efficiency of the crowbar circuit to avoid overcurrents in the generator.

\section{CONTROl Strategy for the RSC Under FAULT CONDITIONS}

\section{A. Feedback of the Stator Currents as the Reference for the RSC}

This proposal intends to design a control strategy for reducing the currents in the stator/rotor windings when a fault affects the generator. The philosophy of this control is to feedback the measured stator currents as the set point for the current controller of the RSC when a voltage dip occurs. In this manner, the current control system synthesizes rotor currents that generate currents waveforms in the stator windings, with the same shape of the currents generated during the sag but in counter phase.

The objective of this strategy is to reduce the stator overcurrents and, as a consequence, the rotor overcurrents that appear in the DFIG windings during the sag, by means of adapting the control of the RSC during this kind of events and without using any external crowbar circuit.

The layout of the proposed strategy is shown in Fig. 6. As it is depicted in the figure, the control system under steady-state conditions would track the PQ references, while the dashed line of the control diagram of the rotor converter is responsible of controlling the DFIG during the voltage sag, when the switch will be placed in position 2 .

When this switch is triggered, the external PQ control loop gets disconnected, and the rotor currents set point matches the measured values of the stator currents in the $d q$ reference frame, 


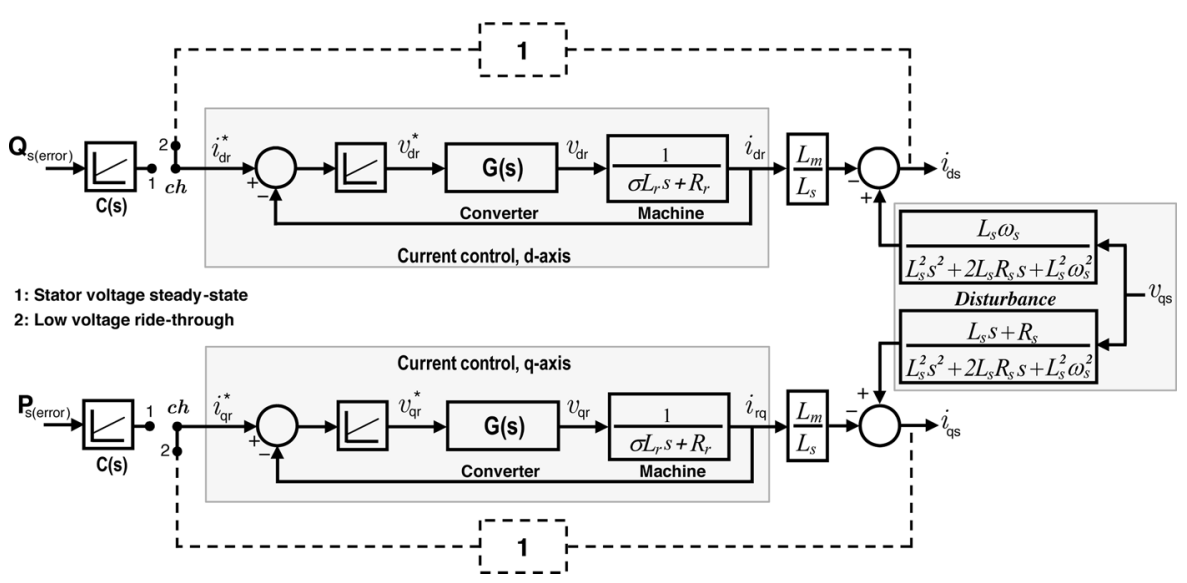

Fig. 6. Layout of the proposed control system for the RSC. The position of the switch is modified from 1 to 2 when the fault is detected, enabling the proposed control strategy during the sag.

as it is indicated in the following:

$$
\begin{aligned}
& i_{\mathrm{dr}}^{*}=i_{\mathrm{ds}} \\
& i_{\mathrm{qr}}^{*}=i_{\mathrm{qs}} .
\end{aligned}
$$

Considering that the current control of the converter is fast and accurate, so that the currents of the rotor track the references given in (13) and (14), then the behavior of the stator currents shown in (8) and (9) can be written as

$$
\begin{aligned}
& i_{\mathrm{ds}}=\frac{1}{L_{\mathrm{s}}+L_{\mathrm{m}}} \frac{\omega_{\mathrm{s}}}{s^{2}+2\left(R_{\mathrm{s}} / L_{\mathrm{s}}\right) s+\omega_{\mathrm{s}}^{2}} v_{\mathrm{qs}} \\
& i_{\mathrm{qs}}=\frac{1}{L_{\mathrm{s}}+L_{\mathrm{m}}} \frac{s+R_{\mathrm{s}} / L_{\mathrm{s}}}{s^{2}+2\left(R_{\mathrm{s}} / L_{\mathrm{s}}\right) s+\omega_{\mathrm{s}}^{2}} v_{\mathrm{qs}} .
\end{aligned}
$$

Through (15) and (16), it can be concluded that the feedback of the stator currents produce an oscillation with an attenuation factor equal to $1 /\left(L_{\mathrm{s}}+L_{\mathrm{m}}\right)$.

It is worth to mention that in the proposed control strategy, the stator currents will be never equal to zero, since there is always a little residual voltage at the PCC. Thus, there is a small magnetizing current $\left(I_{\mathrm{ms}}\right)$ due to the voltage at the machine winding, which is the direct result of the current components of both stator and rotor, $i_{\mathrm{ds}}$ and $i_{\mathrm{dr}}$, each contributing with $50 \%$ of $I_{\mathrm{ms}}$ approximately.

In Fig. 7(a) and (b), the same comparison performed in Fig. 4(a) and (b) is shown. However, in this case, the proposed control strategy is controlling the rotor current during the fault.

\section{B. Grid Fault Detection Based on a DSOGI-FLL}

A good monitoring of the grid voltage is a crucial issue in the implementation of the presented control strategy for the RSC. A rapid detection of any voltage sag at the DFIG windings would permit a fast triggering of the proposed control system that changes the standard current reference for rotor-side current controller, set by the outer active/reactive power control loop, by the direct feedback of the stator currents in counter phase. In this paper, a frequency-locked loop (FLL) system, namely dual second-order generalized integrator-frequencylocked loop (DSOGI-FLL), has been implemented in order to
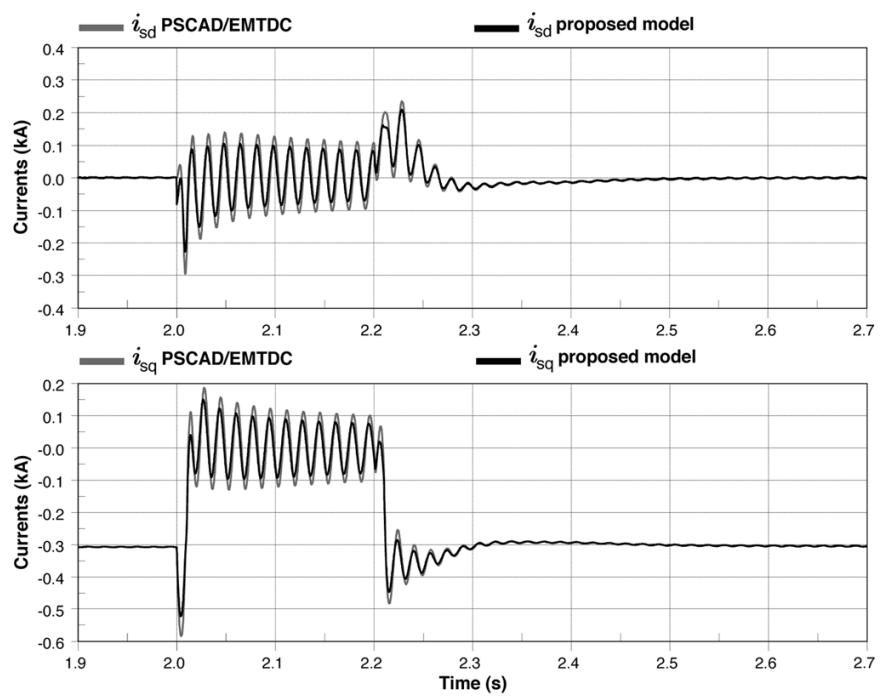

(a)
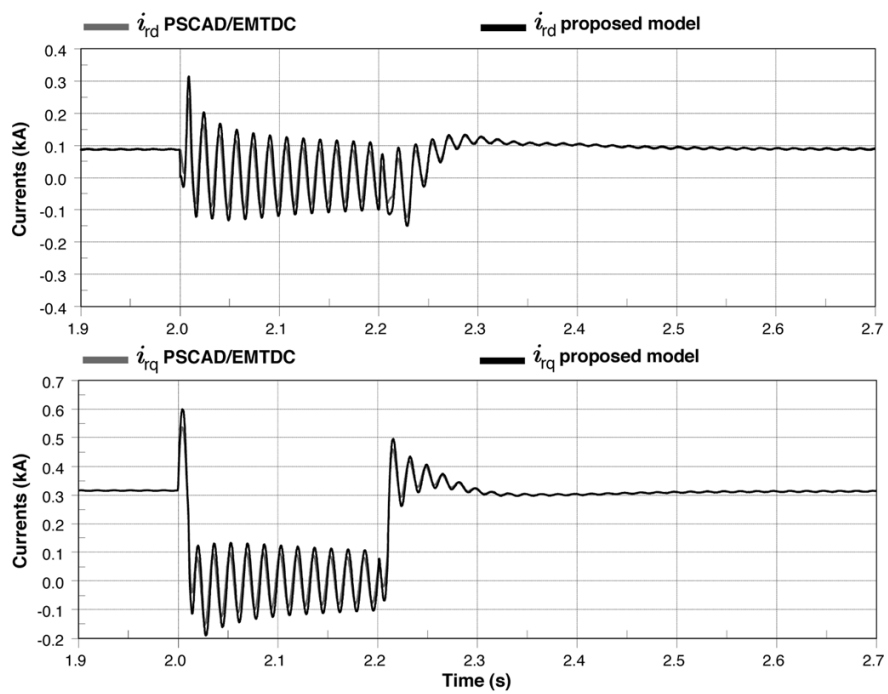

(b)

Fig. 7. Transient response of the stator and rotor currents, with both simplified model and proposed control strategy, when a three phase $70 \%$ depth balanced fault is applied at $t=2.0 \mathrm{~s}$ and cleared after $200 \mathrm{~ms}$. (a) Stator currents. (b) Rotor currents. 


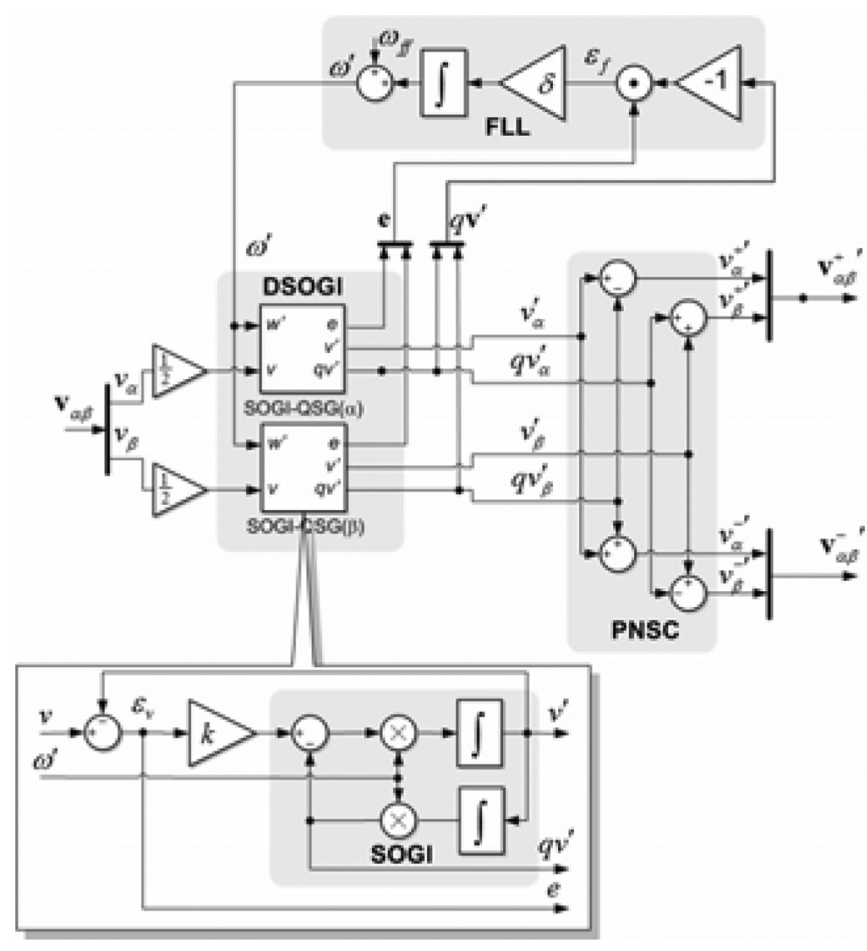

Fig. 8. Block diagram of the DSOGI-FLL.

detect the magnitude of the symmetrical components of the grid voltage at the point of coupling of the DFIG.

This synchronization system was presented in [40], where it was proven its accuracy and fast estimation of the voltage variables under unbalanced and distorted conditions of the electrical network. The layout of the DSOGI-FLL is shown in Fig. 8. The operating principle of the DSOGI-FLL for estimating the positive- and negative-sequence components of the grid voltage vectors is based on using the instantaneous symmetrical components (ISC) method on the $\alpha-\beta$ stationary reference frame [41], [42].

However, in order to apply the ISC method, it is necessary to have a first set of signals $v_{\alpha}-v_{\beta}$ signals representing the input voltage vector on the $\alpha-\beta$ stationary reference frame together with a second set of signals $q v_{\alpha}-q v_{\beta}$, which are inquadrature and lagged respect to $v_{\alpha}-v_{\beta}$. In the DSOGI-FLL, these signals are obtained using a DSOGI, which is an adaptive bandpass filter [43], [44]. As it is detailed in the figure, the DSOGI provides at its output four signals, namely, $v_{\alpha}^{\prime}$ and $v_{\beta}^{\prime}$, which are filtered versions of $v_{\alpha}$ and $v_{\beta}$, respectively, and $q v_{\alpha}^{\prime}$ and $q v_{\beta}^{\prime}$, which are the in-quadrature versions of $v_{\alpha}^{\prime}$ and $v_{\beta}^{\prime}$, respectively.

The main characteristic of the DSOGI-FLL is its frequency adapting loop, i.e., the FLL. Since the DSOGI is an adaptive filter, the fundamental frequency of the grid must be estimated. To match the tuning frequency of the DSOGI to the center frequency of the input signals, an interesting characteristic is exploited, i.e., the error signal provided by the SOGI $(e)$ and its in-quadrature output ( $q v)$ are either in phase or in counter-phase depending on if the frequency of the input signal is either lower or higher than the tuning frequency of the SOGI, respectively.
Therefore, if both signals are multiplied, the dc value of the resulting signal will be either positive or negative as a function of the error in matching the SOGI tuning frequency to the fundamental grid frequency. As can be readily intuited, the integration of the product signal $\left(\varepsilon_{\mathrm{f}}=e q v\right)$ permits obtaining a closed loop (FLL) for canceling out the dc error in frequency estimation, where the dynamics of the loop will be set by the gain $\delta$.

In this work, the estimation of the peak value of the positive sequence of the voltage has been used for triggering the proposed control strategy when this magnitude drops below the $90 \%$ of its nominal value. In order to show the good performance of this estimation, two different experimental tests where this value is estimated when a balanced and unbalanced voltage sag occur are shown in Fig. 9.

Moreover, the elapsed time until the $10 \%$ voltage drop is detected has been measured as well, by means of performing a zoom around the transient of both faults. In Fig. 10(a), the transient in the estimation of the positive sequence is shown. As it can be seen in this figure, the DSOGI-FLL needs only $1.59 \mathrm{~ms}$ to detect the $10 \%$ voltage drop and hence to activate the specific control strategy for protecting the RSC. In Fig. 10(b), the same time has been measured for the unbalanced sag case. Due to the low severity of the fault, the estimation of the voltage drop is slower; however, after $5.97 \mathrm{~ms}$ the fault is detected.

\section{Dynamic Behavior of the Rotor Voltage}

The injection of the rotor currents indicated in (15) and (16) requires a certain voltage at the rotor windings. It is important therefore to determine the performance of this variable, in order to prove the feasibility of this proposal as well as for dimensioning the power converter of the rotor. This section will be devoted to find the time response of the rotor voltage during the fault, giving a special attention to its peak value.

By combining the equations of both voltage and magnetic fluxes of the rotor machine described in (2), and replacing the current equations (15) and (16) found in the previous section, it is possible to determinate the time response of the rotor voltage during the fault.

Although the time response of both $d$ and $q$ axes rotor voltage obtained by this method is somehow complicated, after a few simplifications it results in a second-order system, where the performance of the rotor's voltage depends only on the stator's voltage as in the following:

$$
\begin{aligned}
\frac{v_{\mathrm{qr}}(s)}{v_{\mathrm{qs}}(s)}= & \frac{1}{s^{2}+2 \frac{R_{\mathrm{s}}}{L_{\mathrm{s}}} s+\omega_{\mathrm{s}}^{2}} \\
& \times\left[s\left(s+\frac{R_{\mathrm{s}}}{L_{\mathrm{s}}}\right)+\frac{R_{\mathrm{r}}}{L_{\mathrm{s}}+L_{\mathrm{m}}}\left(s+\frac{R_{\mathrm{s}}}{L_{\mathrm{s}}}\right)+\omega_{\mathrm{slip}} \omega_{\mathrm{s}}\right] \\
\frac{v_{\mathrm{dr}}(s)}{v_{\mathrm{qs}}(s)}= & \frac{1}{s^{2}+2 \frac{R_{\mathrm{s}}}{L_{\mathrm{s}}} s+\omega_{\mathrm{s}}^{2}}\left[\omega_{\mathrm{r}} s+\frac{R_{\mathrm{r}}}{L_{\mathrm{s}}+L_{\mathrm{m}}} \omega_{\mathrm{s}}-\frac{R_{\mathrm{s}}}{L_{\mathrm{s}}} \omega_{\mathrm{slip}}\right]
\end{aligned}
$$




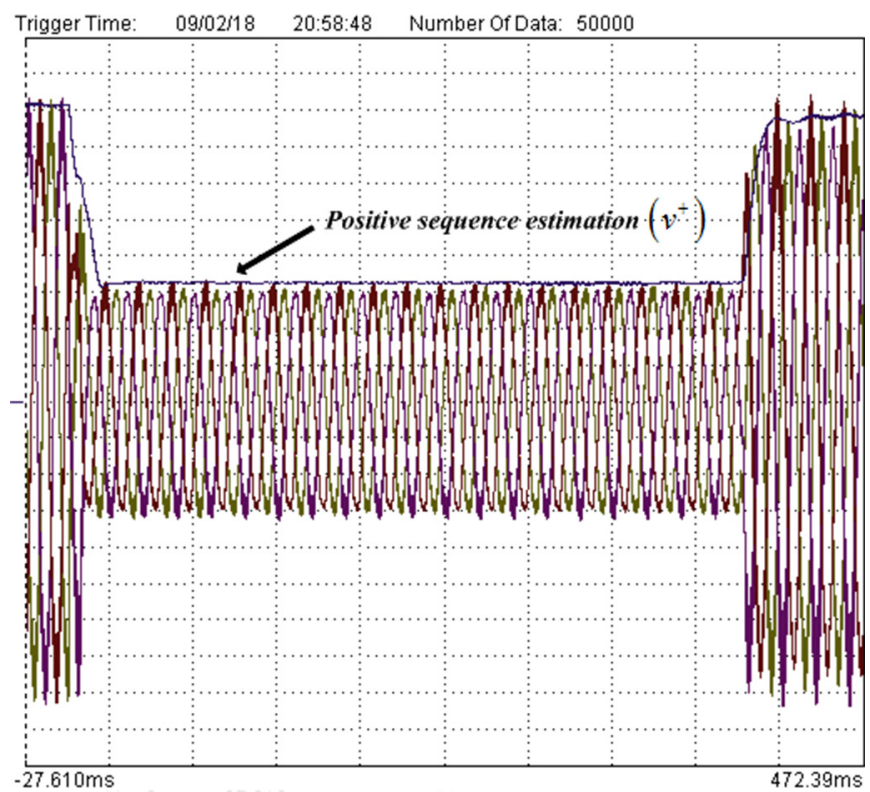

(a)

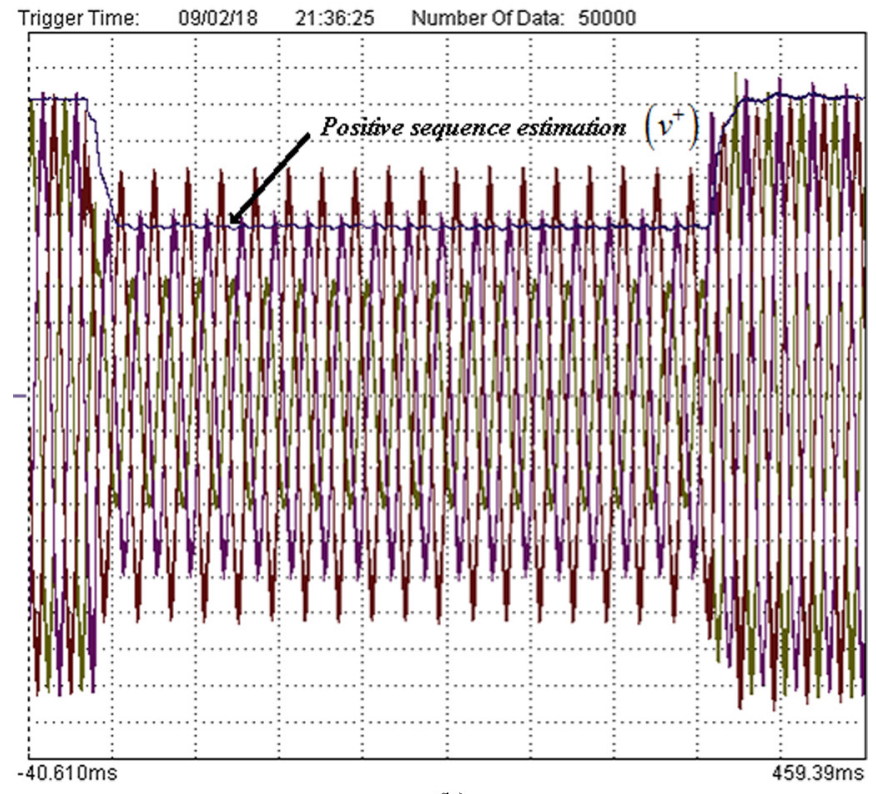

(b)

Fig. 9. Estimation of the positive sequence components of the voltage under grid fault conditions. (a) Balanced voltage sag. (b) Unbalanced voltage sag.

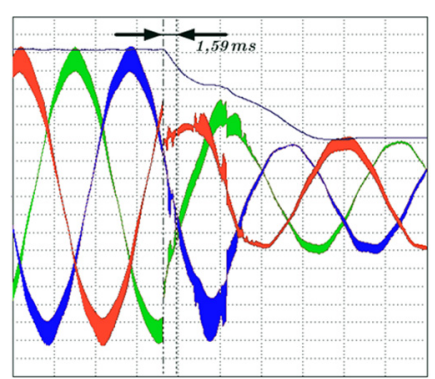

(a)

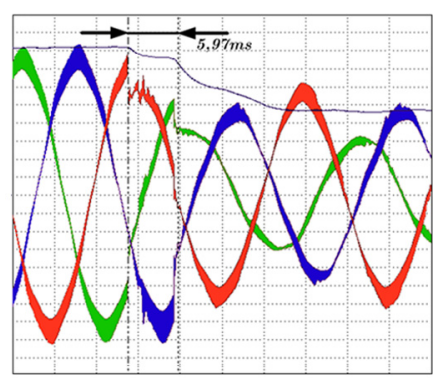

(b)
Fig. 10. Elapsed time until the $10 \%$ voltage drop is detected under faulty situations. (a) Balanced voltage sag. (b) Unbalanced voltage sag.

\section{A. Peak Value for the q-Axis Rotor Voltage}

Applying the inverse Laplace transform in (17) and considering that some coefficients resulting from this operation may be discarded, the resulting $v_{\mathrm{qr}}$ can be written as

$$
v_{\mathrm{qr}}(t)=D\left[\frac{\omega_{\mathrm{slip}}}{\omega_{\mathrm{s}}}+e^{-\frac{R_{\mathrm{s}}}{L_{\mathrm{s}}} t} \sin \omega_{\mathrm{s}} t-\frac{\omega_{\mathrm{slip}}}{\omega_{\mathrm{s}}} e^{-\frac{R_{\mathrm{s}}}{L_{\mathrm{s}}} t} \cos \omega_{\mathrm{s}} t\right]
$$

where $D$ is the magnitude of the voltage sag depth at the stator terminals. In other words, $v_{\mathrm{qs}}$ was considered to be as a step function with a magnitude equal to $D$.

In order to find the maximum value of $v_{\mathrm{qr}}$, it is necessary to differentiate (19) with respect to time and making the result equal to zero. Operating in this manner, the following expression will be obtained:

$$
\gamma \sin \omega_{\mathrm{s}} T_{\mathrm{p}}+\cos \omega_{\mathrm{s}} T_{\mathrm{p}}=0
$$

where $T_{\mathrm{p}}$ is the peak time and $\gamma$ is the slip of machine as defined in the following:

$$
\gamma=\frac{\omega_{\mathrm{s}}-\omega_{\mathrm{r}}}{\omega_{\mathrm{s}}}
$$

As the solution of (20) depends upon two variables, it is possible to write $T_{\mathrm{p}}$ as a function of $\gamma$ as shown in the following:

$$
T_{\mathrm{p}}=\frac{\pi-t g^{-1}(1 / \gamma)}{\omega_{\mathrm{s}}} .
$$

Finally, the maximum value of $v_{\mathrm{qr}}$ can be written as a function of $T_{\mathrm{p}}$ and $\gamma$, as in the following:

$$
V_{\mathrm{qr}(\max )}=D\left(\gamma+e^{-\frac{R_{\mathrm{s}}}{L_{\mathrm{s}}} T_{\mathrm{p}}}\left[\sin \omega_{\mathrm{s}} T_{\mathrm{p}}-\gamma \cos \omega_{\mathrm{s}} T_{\mathrm{p}}\right]\right)
$$

By means of substituting (19) in (20), a simple approximation to predict the peak value of $v_{\mathrm{qr}}$ is obtained, as in the following:

$$
V_{\mathrm{qr}(\max )} \cong D(1+\gamma) \text {. }
$$

\section{B. Peak Value for the d-Axis Rotor Voltage}

The time response of $v_{\mathrm{dr}}$ as well requires some considerations. The first one consists of a simplification of (18), since some terms in the equation can be neglected. The second one is based on the consideration that the voltage at the stator windings during the fault behaves as a step jump with a magnitude equal to $D$.

Once these changes have been made in (18), and after applying the inverse Laplace transform, the resulting function for $v_{\mathrm{dr}}$ can be written as

$$
v_{\mathrm{dr}}(t)=D\left(\frac{\omega_{\mathrm{r}}}{\omega_{\mathrm{s}}} e^{-\frac{R_{\mathrm{s}}}{L_{\mathrm{s}}} t} \sin \omega_{\mathrm{s}} t\right) .
$$

As in the previous case differentiating (25) with respect to time and making the result equal to zero, the following expression is obtained:

$$
\operatorname{tg}\left(\omega_{\mathrm{s}} T_{\mathrm{p}}\right)-\frac{L_{\mathrm{s}}}{R_{\mathrm{s}}} \omega_{\mathrm{s}}=0
$$


Solving (26) for $T_{\mathrm{p}}$, the result is given by

$$
T_{\mathrm{p}}=\frac{\operatorname{tg}^{-1}\left(\left(L_{\mathrm{s}} / R_{\mathrm{s}}\right) \omega_{\mathrm{s}}\right)}{\omega_{\mathrm{s}}}
$$

The maximum value of $v_{\mathrm{dr}}$ can be expressed now in function of $T_{\mathrm{p}}$, that is the time when the peak value is reached, yielding finally the following equation.

$$
V_{\mathrm{dr}(\max )}=D\left(\frac{\omega_{\mathrm{r}}}{\omega_{\mathrm{s}}} e^{-\frac{R_{\mathrm{s}}}{L_{\mathrm{s}}} T_{\mathrm{p}}} \sin \omega_{\mathrm{s}} T_{\mathrm{p}}\right) .
$$

Using the slip definition written in (21), (28) can be reduced to a simple approximation of $V_{\mathrm{dr}(\max )}$ as a function of $D$ and $\gamma$ as in the following:

$$
V_{\mathrm{dr}(\max )} \cong D(1-\gamma) .
$$

\section{Maximum Amplitude of the Rotor Voltage Vector}

The peak amplitude of the estimated voltage in the rotor when using this strategy can be finally calculated adding the $d q$ components found in (24) and (29). The addition of both vectors gives rise to the following equation that evidence the linear dependence of $V_{\mathrm{r}}$ with the fault depth and the relationship with the slip of the machine when the sag occurs.

$$
V_{\mathrm{r}(\max )} \cong \sqrt{2} \sqrt{1+\gamma^{2}} D .
$$

Thus, the maximum value of $V_{\mathrm{r}}$ in function of the voltage depth, considering the most critical conditions, where the slip of the DFIG's rotor would be maximum, $\gamma=0.30$, could be obtained as

$$
V_{\mathrm{r}(\max )} \cong 1.48 D .
$$

As it can be concluded from the last equation, if the machine is operating under generic conditions, the maximum amplitude of the rotor voltage will be $48 \%$ higher than the magnitude of the voltage sag. Nevertheless, a more detailed analysis of this peak value could be performed, thanks to Figs. 11 and 12. In Fig. 11, the $V_{\mathrm{r}(\max )}$ is represented as a function of $\gamma$ and $D$, yielding a surface that can be cut by different auxiliary horizontal planes in the z-axis that represent different boundaries for $V_{\mathrm{r}(\max )}$.

Depending on the maximum admissible voltage at the output of the converter one or another plane would be selected. Finally, if several planes are considered and the different intersections with the $V_{\mathrm{r}}$ surface are castled in the $\gamma-D$ plane, the diagram shown in Fig. 12 would be obtained. This figure intends to determine the maximum voltage depth that can be withstood by the system without over passing a certain limit of $V_{\mathrm{r}}$. In this particular case, the graph shows the fault boundaries if no more than $1.0 \mathrm{~V}$ (p.u.) should appear at the rotor windings. The shadowed area that encloses the permissible $\gamma-D$ margin can be considered as the feasible region for voltage rotor peaks under 1.0 (p.u.).

In the following section, the accuracy of this estimation would be tested, as well as the performance of the proposed algorithm regarding the current control at the rotor side by means of PSCAD/EMTDC simulations.

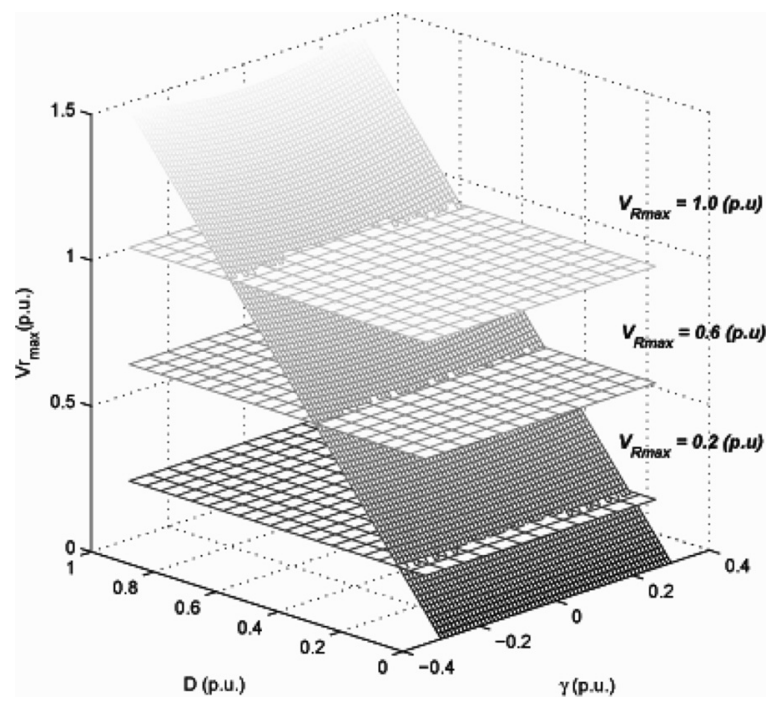

Fig. 11. Surface of $V_{\mathrm{r}(\max )}$ in function of the slip $(\gamma)$ and the fault depth $D$.

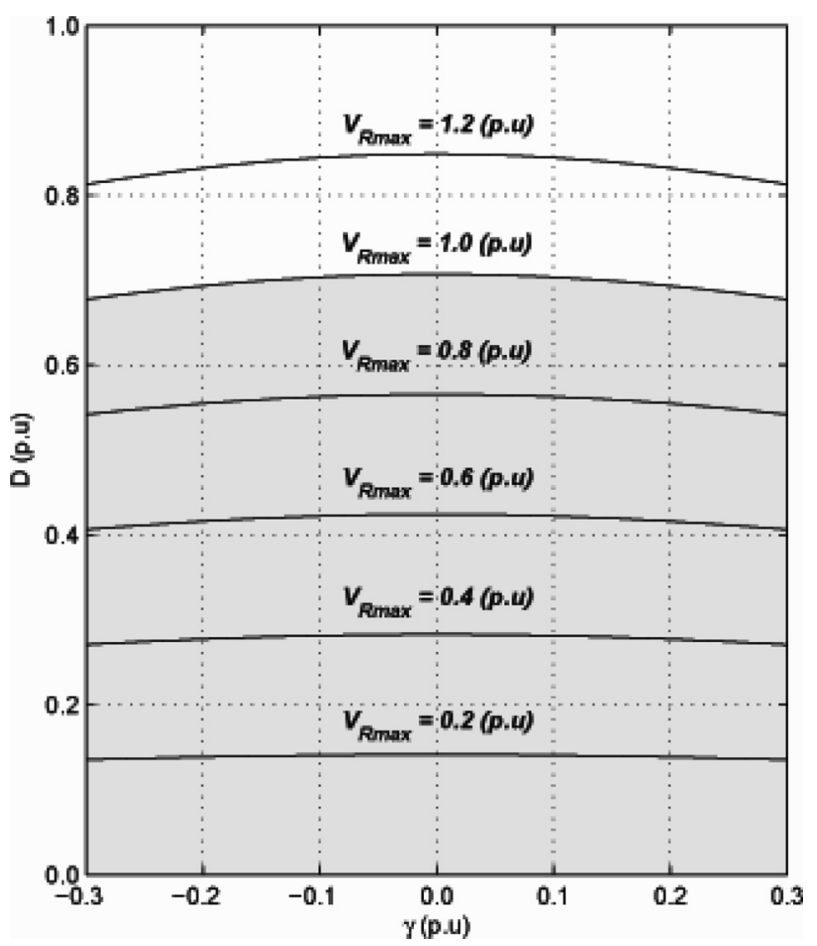

Fig. 12. Feasible regions depending on the maximum admissible $V_{\mathrm{r}}$. The shadowed area show the fault boundaries for a $V_{\mathrm{r}(\max )} \leq 1.0$ (p.u.).

\section{Simulation Results}

The performances of the discussed strategy have been tested considering a three-phase balanced voltage sag, produced by a three-phase short circuit in the distribution grid. The voltage waveforms during the sag are depicted in Fig. 13(a).

As it can be noticed in Fig. 13(b), the proposed control strategy permits to reduce the currents in the generator's windings during the fault. The soft damping of the oscillations in the currents, which can be noticed in the figure, are due to the 


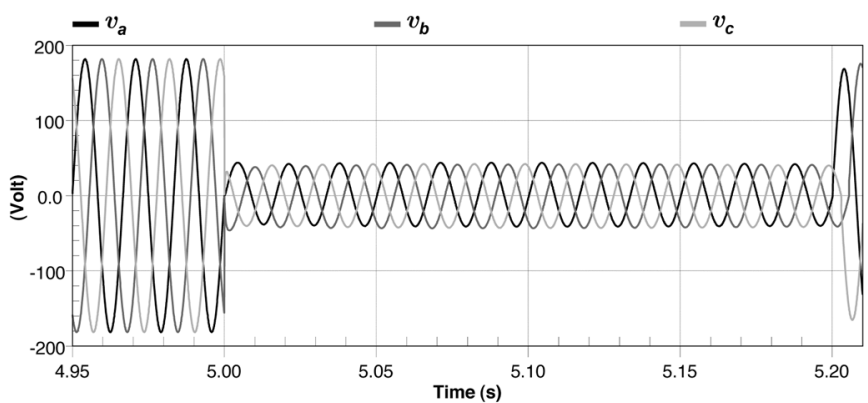

(a)

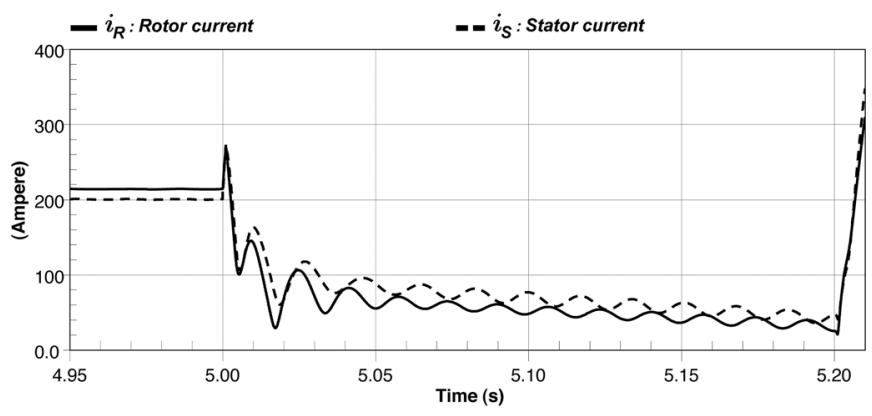

(b)

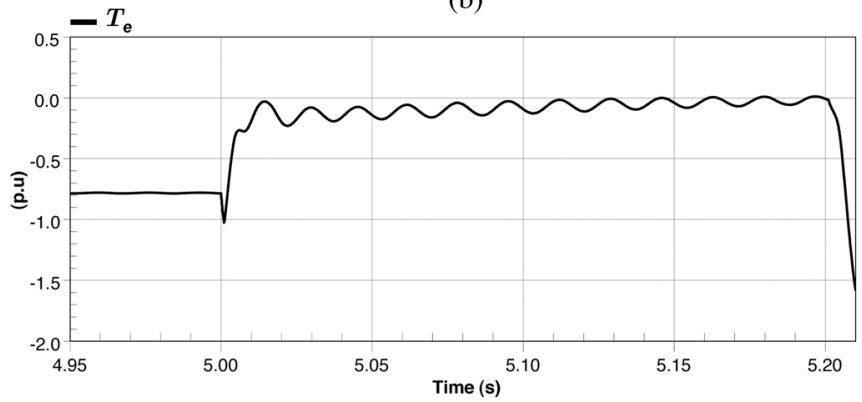

(c)

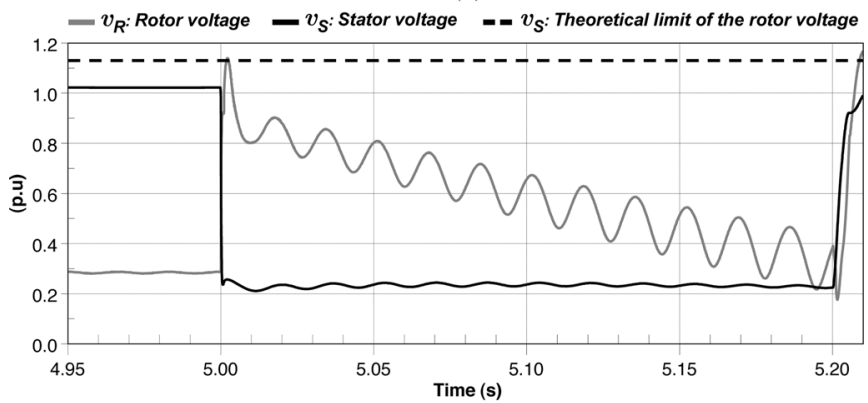

(d)

Fig. 13. Behavior of the rotor voltage and currents when a balanced sag is applied at $t=5 \mathrm{~s}$ and cleared after $200 \mathrm{~ms}$. (a) Voltage at the PCC during the balanced sag produced in $t=5 \mathrm{~s}$ and cleared after $200 \mathrm{~ms}$. (b) Rotor and stator currents performance under balanced sag conditions. (c) Behavior of the electromagnetic torque during balanced sag. (d) Dynamic behavior of the rotor and stator voltage during voltage sag.

relationship between the stator resistance and the magnetizing inductance that yields a low damping factor. These results match the response predicted by the models presented in (15) and (16). Besides, in this part, it is worth to point out that in this particular case the natural oscillation of the system has the same frequency of the grid $\omega_{\mathrm{s}}$. This occurs because the voltage sag is balanced, and hence it contains a single positive sequence component. In

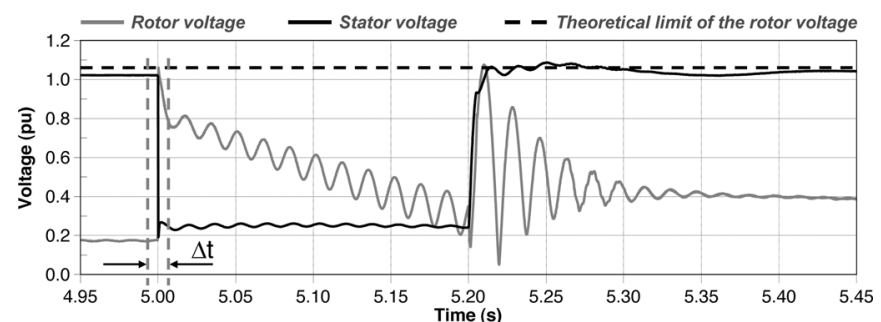

(a)

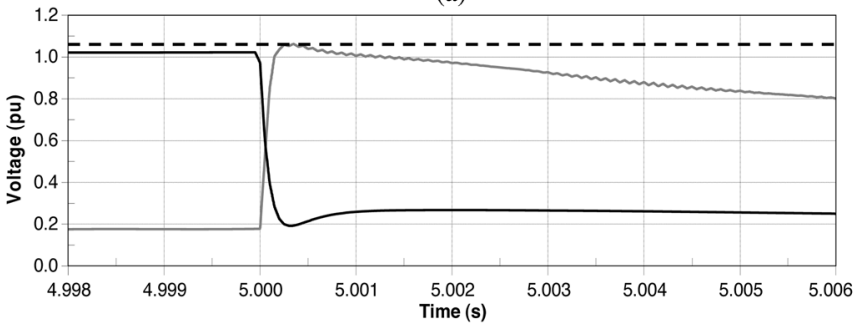

(b)

Fig. 14. (a) Rotor voltage behavior during a balanced voltage sag. (b) Zoomed area, $\Delta t$, that show the initial ms of the fault.

Fig. 13(c), the dynamics of the torque is displayed, showing that this strategy does not produce a high ripple of this magnitude, something that would be harmful from the mechanical point of view. Finally, the response of the filtered rotor voltage during the fault has been displayed in Fig. 13(d). As it can be noticed, the voltage in the rotor windings does not overpass the estimated maximum that has been calculated, thanks to (30), which appears in the plot as a dashed horizontal line.

In order to make sure that the analytical equations match the simulation results, another simulation of a balanced sag has been performed. In this case, only the rotor and stator voltage behavior has been collected, as it is shown in Fig. 14. As a difference with the previous simulation, the phase angle of the fault has been changed. As it can be noticed in Fig. 14(a) and even with a higher clarity in the zoom available in Fig. 14(b), the theoretical peak of the rotor's voltage is predicted correctly as well.

\section{EXPERIMENTAL RESULTS}

The performance of the presented strategy has been tested in a scaled experimental setup, where not only the capability for reducing the rotor currents under fault conditions with the proposed strategy has been tested but also the evolution of the rotor voltage has been monitored.

The layout of the experimental workbench is depicted in Fig. 15. In this study case, a 7.5 kW DFIG has been used, whose parameters are summarized in Table II. As it can be noticed from the figure, the input mechanical torque has been controlled by means of a DC motor that emulates the behavior of the WT blades, which are directly linked to the shaft of the generator. The stator of the machine is connected to the grid by means of a delta-wye transformer, while the rotor windings are connected to a $5.5 \mathrm{~kW}$ power converter. The same kind of inverter was used also as front-end converter for controlling the dc-bus voltage. As it is shown in the diagram, in order to produce voltage sag at 


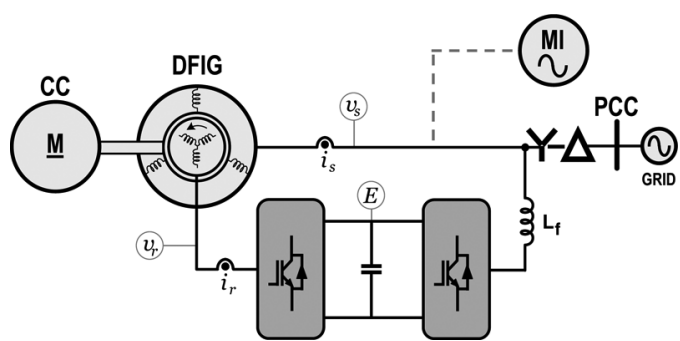

Fig. 15. Block diagram of the experimental setup.

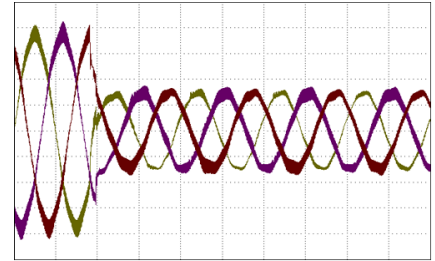

(a)

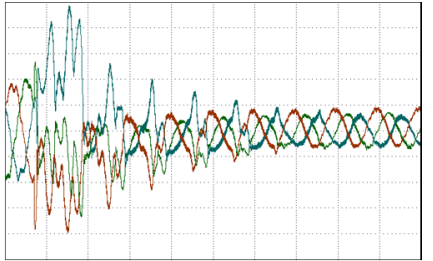

(b)
Fig. 16. Voltage and currents at the stator of the DFIG when a balanced $63 \%$ voltage drop occurs due to the SCIM connection. The initial slip of the DFIG is $20 \%$. (a) Stator voltage $50 \mathrm{~V} /$ div. (b) Stator current 2 A/div.

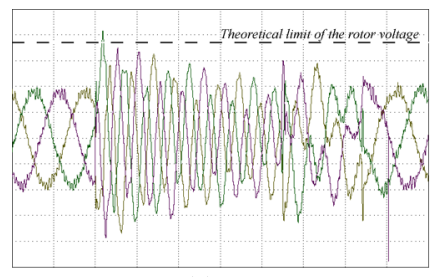

(a)

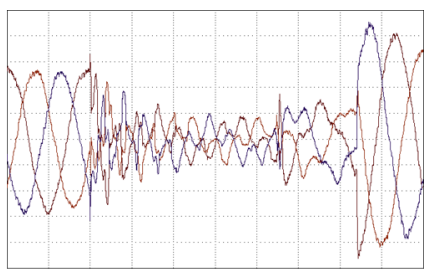

(b)
Fig. 17. Voltage and currents at the rotor of the DFIG when a $63 \%$ balanced voltage drop occurs due to the SCIM connection. The initial slip of the DFIG is $20 \%$. (a) Rotor voltage $40 \mathrm{~V} / \mathrm{div}$. (b) Rotor current $2 \mathrm{~A} / \mathrm{div}$.

the point of coupling of the generator, a squirrel cage induction machine (SCIM) was directly connected to the stator windings. The high inrush currents drained by the SCIM produce a voltage drop in the grid, due to the impedance of the network, permitting thus to evaluate the performance of the proposed strategy under such conditions.

In the first test, the SCIM was powered up while the DFIG was injecting $0.5 \mathrm{~kW}$ to the grid rotating at $1200 \mathrm{rpm}(20 \%$ of slip). In Fig. 16(a), the voltages at the stator windings are shown, where it can be clearly noticed how the connection of the SCIM makes the voltage drop from $225 \mathrm{~V}$ to $83 \mathrm{~V}$, producing thus a balanced 63\% sag. In Fig. 16(b), the overcurrents that appear at the stator of the DFIG, as a consequence of the demagnetization of the machine, are shown as well.

In Fig. 17(a) and (b), the behavior of the voltage and the currents at the RSC are shown. The good performance of the proposed control system can be appreciated in Fig. 17(b), where it is clear how the currents at the rotor winding are reduced, avoiding the tripping of the RSC. In addition, the monitoring of the peak value in the rotor voltage, around $144 \mathrm{~V}$ as shown in Fig. 17(a), permits also to prove that this peak can be predicted, thanks to (30).

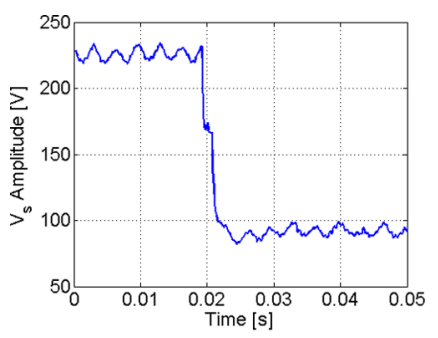

(a) (b)

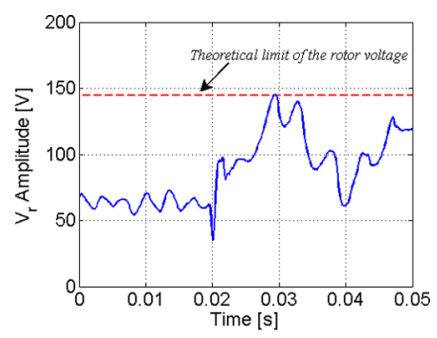

Fig. 18. Voltage and currents at the rotor of the DFIG when a $63 \%$ balanced voltage drop occurs due to the SCIM connection. The initial slip of the DFIG is $20 \%$. (a) Stator voltage. (b) Rotor voltage.

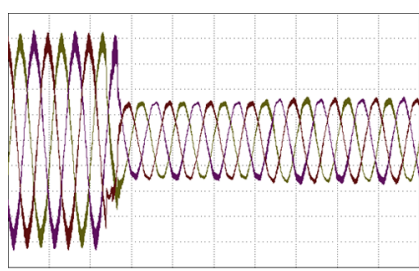

(a)

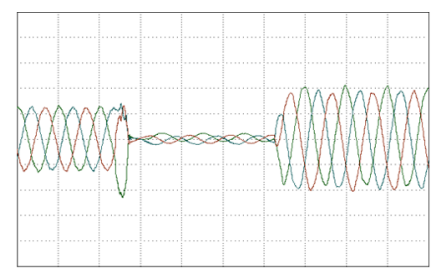

(b)
Fig. 19. Voltage and currents at the stator of the DFIG when a $67 \%$ balanced voltage drop occurs due to the SCIM connection. The initial slip of the DFIG is $20 \%$. (a) Stator voltage $50 \mathrm{~V} /$ div. (b) Stator current $5 \mathrm{~A} /$ div.

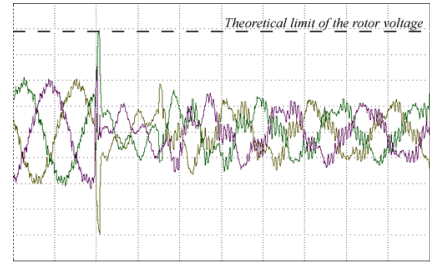

(a)

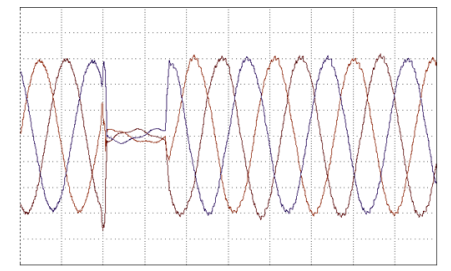

(b)
Fig. 20. Voltage and currents at the rotor of the DFIG when a $67 \%$ balanced voltage drop occurs due to the SCIM connection. The initial slip of the DFIG is $20 \%$. (a) Rotor voltage $40 \mathrm{~V} / \mathrm{div}$. (b) Rotor current $2 \mathrm{~A} / \mathrm{div}$.

The same results were collected, thanks to a voltage acquisition board, which was directly connected to the control setup. In Fig. 18(a), the magnitude of the stator voltage is shown, and in Fig. 18(b), a comparison between the real value of the voltage and the estimated peak value has been displayed. As it can be realized, the estimation matches very well with the real value.

In order to test the feasibility of the rotor voltage peak calculation, another experimental test has been performed considering a $20 \%$ of slip in the DFIG, but with a sag depth equal to $67 \%$, when connecting the SCIM. This second experiment was performed delivering more active power before the fault than in the previous case. In addition, reactive power has been injected through the stator after the rotor currents are under control. The experimental results collected in this case at the stator side are displayed in Fig. 19.

In this case, the depth of the voltage dip is $67 \%$, as shown in Fig. 19(a), producing the same effect on the stator currents, available in Fig. 19(b).

The behavior of the rotor voltage in the transient is shown in Figs. 20(a) and 21(b). In this case, considering the depth 


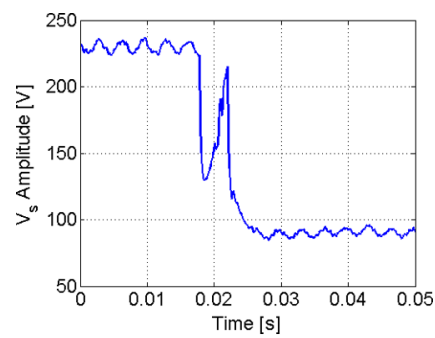

(a)

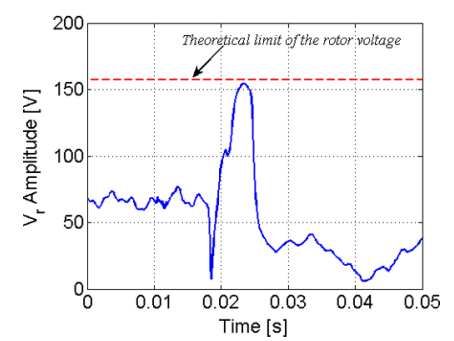

(b)
Fig. 21. Voltage and currents at the rotor of the DFIG when a $67 \%$ balanced voltage drop occurs due to the SCIM connection. The initial slip of the DFIG is $20 \%$. (a) Stator voltage. (b) Rotor voltage.

of the voltage sag as well as the slip of the generator, it can be proven that the voltage peak in the rotor, that is equal to $157 \mathrm{~V}$, coincides with the foreseen value that can be found, thanks to the expression deducted in Section IV. The theoretical value was equal to $157 \mathrm{~V}$, while the real value reached $154 \mathrm{~V}$ [see Fig. 21(b)], which represents an error less then $2 \%$. These results show that the maximum value for the rotor voltage can be determined using (30).

In Fig. 20(b), it can be observed how the currents in the rotor can be controlled after few milliseconds, thanks to the proposed control strategy. Once the overcurrents are avoided, the injection of reactive power is enabled, as it can be noticed in Fig. 20(b) where the current increases rapidly after $60 \mathrm{~ms}$ giving rise to reactive power injection into the network.

As in the previous case, the behavior of the stator and rotor voltage are shown in Fig. 21(a) and (b) in order to show how the magnitude of the voltage reaches the estimated peak value.

\section{CONCLUSION}

In this paper, the modeling of a DFIG, considering the behavior of the generator when transients in the stator voltage occur, was developed. Thanks to this model that permits to predict the performance of a DFIG under fault scenarios, a novel control strategy for the rotor-side controllers, oriented to enhance its response during severe voltage sags, was proposed.

This strategy is based on using the measured stator current values as the set point for the rotor current controller during the fault. As it has been demonstrated, in this way, it is possible to synthesize a current in the stator in opposition to the currents generated during the fault, preventing thus the stator/rotor windings from suffering overcurrents, with no need of using crowbar circuits.

A theoretical analysis of the dynamical behavior of the rotor voltage during a fault when applying the proposed control strategy was performed as well in order to study the feasibility of this proposal. Equations developed in this analysis leads to conclude that amplitude values achieved by rotor voltage vector stay under safe limits.

Therefore, the results presented in this paper show that it is possible to control the stability of a DFIG during severe contingencies in the power network, without the need of external auxiliary circuits. This issue enables the rotor-side power converter to remain connected to the grid in faulty scenarios without getting damaged, something that, as a difference with applications based on crowbar circuits, permits to implement specific strategies in order to boost the voltage at the PCC during the fault as the new GCs demand.

\section{APPENDIX}

Tables I and II gather the parameters of the DFIG used in the simulation and experimental tests of this paper.

TABLE I

SPECIFICATION OF THE SIMULATED SYSTEMS

\begin{tabular}{ll}
\hline \multicolumn{1}{c}{ Machine parameters } & \multicolumn{1}{c}{ Values } \\
\hline Rated power & $100 \mathrm{kVA}$ \\
Rated stator voltage & $220 \mathrm{~V}$ \\
Rated rotor voltage & $220 \mathrm{~V}$ \\
Rated estator current & $340 \mathrm{~A}$ \\
Rated stator frequency & $60 \mathrm{~Hz}$ \\
Stator resistance & $2.6 \mathrm{~m} \Omega$ \\
Rotor resistance & $2.9 \mathrm{~m} \Omega$ \\
Stator leakage inductance & $138.66 \mu \mathrm{H}$ \\
Rotor leakage inductance & $141.22 \mu \mathrm{H}$ \\
Mutual inductance & $5.6 \mathrm{mH}$ \\
Angular moment of inertia $(\mathrm{J}=2 \mathrm{H})$ & $0.5 \mathrm{pu}$ \\
Poles pairs & 1 \\
\hline
\end{tabular}

TABLE II

SPECIFICATION OF THE EXPERIMENTAL SETUP

\begin{tabular}{ll}
\hline \multicolumn{1}{c}{ DFIG parameters } & \multicolumn{1}{c}{ Values } \\
\hline Rated power & $7.5 \mathrm{kVA}$ \\
Rated stator voltage & $220 \mathrm{~V}$ \\
Rated stator frequency & $50 \mathrm{~Hz}$ \\
Stator resistance & $0.462 \mathrm{~m} \Omega$ \\
Rotor resistance & $0.473 \mathrm{~m} \Omega$ \\
Stator leakage inductance & $3.93 \mathrm{mH}$ \\
Rotor leakage inductance & $3.93 \mathrm{mH}$ \\
Mutual inductance & $103.4 \mathrm{mH}$ \\
Turns ratio & 1 \\
Poles pairs & 2 \\
\hline \multicolumn{1}{c}{ Power converters } & Values \\
\hline Rated power & $5 \mathrm{~kW}$ \\
Rated stator voltage & $380 \mathrm{~V}$ \\
Rated nominal current & $7 \mathrm{~A}$ \\
\hline & Dus \\
\hline DC Voltage & $500 \mathrm{~V}$ \\
Capacitance & $4.7 \mathrm{mF}$ \\
\hline
\end{tabular}

\section{REFERENCES}

[1] I. Erlich, W. Winter, and A. Dittrich, "Advanced grid requirements for the integration of wind turbines into the German transmission system," in Proc. Power Eng. Soc. Gen. Meet., Jun. 2006, p. 7.

[2] A. Morales, X. Robe, M. Sala, P. Prats, C. Aguerri, and E. Torres, "Advanced grid requirements for the integration of wind farms into the Spanish transmission system," IET Renewable Power Gen., vol. 2, no. 1, pp. 4759, 2008.

[3] E-ON Netz GmbH. (2006, Apr.) Grid code-High and extra high voltage. [Online]. Available: http://www.eon-netz.com

[4] Grid Electricity Transmission. (2008, Oct.) "The grid code: Revision 31," in United Kingdom no. 3 [Online]. Available: http://www.nationalgrid. com/uk 
[5] Comisión Nacional de Energía, "PO-12.3 Requisitos de respuesta frente a huecos de tensión de las instalaciones eólicas," (in Spanish), Oct. 2006. Available: www.depeca.uah.es/docencia/ING-ECA/EI/P.O.12.3. pdf

[6] Transmission Lines Department (Denmark). (2004, May). Wind turbines connected to grids with voltages below $100 \mathrm{kV}$-Technical Regulations TF 3.2.6 [Online]. Available: http://www.energinet.dk 2010.

[7] B. M. Buchholz, Z. A. Styczynski, and W. Winter, "Dynamic simulation of renewable energy sources and requirements on fault ride through behavior," in Proc. IEEE Power Eng. Soc. Gen. Meet., 18-22 Jun. 2006, p. 7.

[8] P. Krause, O. Wasynczuk, and S. Sudhoff, Analysis of Electric Machinery and Drive Systems, 2nd ed. New York: IEEE Press, 2002.

[9] F. Blaabjerg and Z. Chen, Power Electronics for Modern Wind Turbines, 1st ed.. USA: Morgan \& Claypool, 2006.

[10] D. Xiang, L. Ran, P. J. Tavner, and S. Yang, "Control of a doubly-fed induction generator in a wind turbine during grid fault ride-through," IEEE Trans. Energy Convers., vol. 21, no. 3, pp. 652-662, Sep. 2006

[11] J. Lopez, P. Sanchis, X. Roboam, and L. Marroyo, "Dynamic behavior of the doubly fed induction generator during three-phase voltage dips," IEEE Trans. Energy Convers., vol. 22, no. 3, pp. 709-717, Sep. 2007.

[12] F. Mei and B. Pal, "Modal analysis of grid-connected doubly fed induction generators," IEEE Trans. Energy Convers., vol. 22, no. 3, pp. 728-736, Sep. 2007.

[13] L. Xu and P. Cartwright, "Direct active and reactive power control of DFIG for wind energy generation," IEEE Trans. Energy Convers., vol. 21, no. 3, pp. 750-758, Sep. 2007.

[14] R. Fadaeinedjad, M. Moallem, and G. Moschopoulos, "Simulation of a wind turbine with doubly fed induction generator by FAST and simulink," IEEE Trans. Energy Convers., vol. 23, no. 2, pp. 690-700, Jun. 2008.

[15] J. Lopez, E. Gubia, P. Sanchis, X. Roboam, and L. Marroyo, "Wind turbines based on doubly fed induction generator under asymmetrical voltage dips," IEEE Trans. Energy Convers., vol. 23, no. 1, pp. 321-330, Mar. 2008.

[16] M. Kayikci and J. V. Milanovic, "Reactive power control strategies for DFIG-based plants," IEEE Trans. Energy Convers., vol. 22, no. 2, pp. 389 396, Jun. 2007

[17] T. K. A. Brekken and N. Mohan, "Control of a doubly fed induction wind generator under unbalanced grid voltage conditions," IEEE Trans. Energy Convers., vol. 22, no. 1, pp. 129-135, Mar. 2007.

[18] L.-R. Chang-Chien, C.-M. Hung, and Y.-C. Yin, "Dynamic reserve allocation for system contingency by DFIG wind farms," IEEE Trans. Power Syst., vol. 23, no. 2, pp. 729-736, May 2008.

[19] S. Seman, J. Niiranen, and A. Arkkio, "Ride-through analysis of doubly fed induction wind-power generator under unsymmetrical network disturbance," IEEE Trans. Power Syst., vol. 21, no. 4, pp. 1782-1789, Nov. 2006.

[20] G. Iwanski and W. Koczara, "DFIG-based power generation system with UPS function for variable-speed applications," IEEE Trans. Ind. Electron., vol. 55, no. 8, pp. 3047-3054, Aug. 2008.

[21] F. Bonnet, P.-E. Vidal, and M. Pietrzak-David, "Dual direct torque control of doubly fed induction machine," IEEE Trans. Ind. Electron., vol. 54, no. 5, pp. 2482-2490, Oct. 2007.

[22] P. S. Flannery and G. Venkataramanan, "A fault tolerant doubly fed induction generator wind turbine using a parallel grid side rectifier and series grid side converter," IEEE Trans. Power Electron., vol. 23, no. 3, pp. 1126-1135, May 2008.

[23] L. Xu, "Coordinated control of DFIG's rotor and grid side converters during network unbalance," IEEE Trans. Power Electron., vol. 23, no. 3, pp. 1041-1049, May 2008.

[24] W. Qiao, W. Zhou, J. M. Aller, and R. G. Harley, "Wind speed estimation based sensorless output maximization control for a wind turbine driving a DFIG," IEEE Trans. Power Electron., vol. 23, no. 3, pp. 1156-1169, May 2008.

[25] K. Protsenko and D. Xu, "Modeling and control of brushless doubly-fed induction generators in wind energy applications," IEEE Trans. Power Electron., vol. 23, no. 3, pp. 1191-1197, May 2008.

[26] J. Yao, H. Li, Y. Liao, and Z. Chen, "An improved control strategy of limiting the DC-link voltage fluctuation for a doubly fed induction wind generator," IEEE Trans. Power Electron., vol. 23, no. 3, pp. 1205-1213, May 2008.
[27] G. Abad, M. A. Rodriguez, and J. Poza, "Two-level VSC based predictive direct torque control of the doubly fed induction machine with reduced torque and flux ripples at low constant switching frequency," IEEE Trans. Power Electron., vol. 23, no. 3, pp. 1050-1061, May 2008.

[28] R. Cardenas, R. Pena, J. Clare, G. Asher, and J. Proboste, "MRAS observers for sensorless control of doubly-fed induction generators," IEEE Trans. Power Electron., vol. 23, no. 3, pp. 1075-1084, May 2008.

[29] D. Santos-Martin, J. L. Rodriguez-Amenedo, and S. Arnalte, "Direct power control applied to doubly fed induction generator under unbalanced grid voltage conditions," IEEE Trans. Power Electron., vol. 23 , no. 5, pp. 2328-2336, Sep. 2008.

[30] D. Santos-Martin, J. L. Rodriguez-Amenedo, and S. Arnalte, "Dynamic programming power control for doubly fed induction generators," IEEE Trans. Power Electron., vol. 23, no. 5, pp. 2337-2345, Sep. 2008

[31] M. Kayikci and J. V. Milanovic, "Assessing transient response of DFIGbased wind plants The influence of model simplifications and parameters," IEEE Trans. Power Syst., vol. 23, no. 2, pp. 545-554, May 2008.

[32] J. Morren and S. W. H. de Haan, "Ride through of wind turbine with doubly-fed induction generator during a voltage dip," IEEE Trans. Energy Convers., vol. 20, no. 2, pp. 435-441, Jun. 2005.

[33] B. I. Næss, M. Molinas, and T. Undeland, "Laboratory tests of ride through for doubly fed induction generators," presented at the Nordic Wind Power Conf., Espoo, Finland, May 22-23, 2006.

[34] J. Morren and S. W. H. de Haan, "Short-circuit current of wind turbines with doubly fed induction generator," IEEE Trans. Energy Convers., vol. 22, no. 1, pp. 174-180, Mar. 2007.

[35] I. Erlich, J. Kretschmann, J. Fortmann, S. Mueller-Engelhardt, and H. Wrede, "Modeling of wind turbines based on doubly-fed induction generators for power system stability studies," IEEE Trans. Power Syst., vol. 22, no. 3, pp. 909-919, Aug. 2007.

[36] C. Abbey and G. Joos, "Effect of low voltage ride through (LVRT) characteristic on voltage stability," in Proc. IEEE Power Eng. Soc. Gen. Meet., 2005, vol. 2, pp. 1901-1907.

[37] F. Iov, A. Hansen, P. Sorensen, and N. Cutululis, "Mapping of grid faults and grid codes-Risoe-R-1617(EN)," presented at the Risø Nat. Lab. Roskilde, Denmark, Jun. 2007.

[38] W. Leonhard, Control of Electrical Drives, 3rd ed. New York: SpringerVerlag, 2001.

[39] F. K. A. Lima and E. H. Watanabe, "Parallel connection of doubly-fed induction generator in wind generation," in Proc. 9th Power Electron. Brazilian Conf., 2007, vol. 9, pp. 631-639.

[40] P. Rodriguez, A. Luna, M. Ciobotaru, R. Teodorescu, and F. Blaabjerg, "Advanced grid synchronization system for power converters under unbalanced and distorted operating conditions," in Proc. IEEE Ind. Electron. Conf. (IECON 2006), Nov., pp. 5173-5178.

[41] C. L. Fortescue, "Method of symmetrical coordinates applied to the solution of polyphase networks," Trans. AIEE, vol. 37, pt. II, pp. 1027-1140, 1918.

[42] W. V. Lyon, Application of the Method of Symmetrical Components. New York: McGraw-Hill, 1937.

[43] X. Yuan, W. Merk, H. Stemmler, and J. Allmeling, "Stationary frame generalized integrators for current control of active power filters with zero steady-state error for current harmonics of concern under unbalanced and distorted operating conditions," IEEE Trans. Ind. Appl., vol. 38, no. 2, pp. 523-532, Mar./Apr. 2002.

[44] M. Ciobotaru, R. Teodorescu, and F. Blaabjerg, "A new single-phase PLL structure based on second order generalized integrator," in Proc. IEEE Power Electron. Spec. Conf. (PESC 2006), Jun., pp. 1-7.

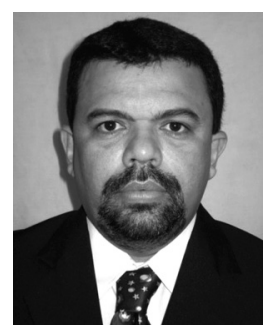

Francisco K. A. Lima received the B.S. and M.S. degrees in electrical engineering from the Federal University of Ceara, Fortaleza-Ceara, Brazil, in 1998 and 2003, respectively. Currently, he is working toward the Ph.D. degree at the COPPE/Federal University of Rio de Janeiro, Rio de Janeiro, Brazil.

His recent research interests include wind power generation, power quality, system control, and topology analysis for power converters. 


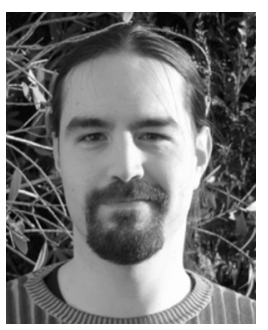

Alvaro Luna (S'07) received the B.S. and M.S. degrees in electrical engineering from the Universitat Politecnica de Catalunya (UPC), Barcelona, Spain, in 2001 and 2005, where he is currently working toward the Ph.D. degree.

In 2005, he joined the faculty of UPC as an Assistant Professor.

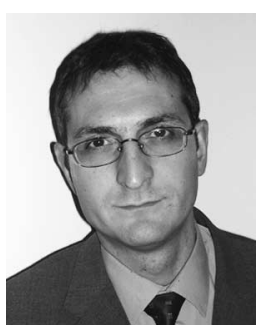

Pedro Rodriguez (S'01-A'03-M'04) received the M.S. and Ph.D. degrees in electrical engineering from the Technical University of Catalonia (UPC), Barcelona, Spain, in 1994 and 2004, respectively.

In 1990, he joined the faculty of UPC as an Assistant Professor, where he is currently an Associate Professor. In 2005, he was a Visiting Researcher in the Center for Power Electronics Systems, Virginia Tech. In 2006 and 2007, he was a Postdoctoral researcher in the Institute of Energy Technology, Aalborg University (AAU), Denmark, where he lectures $\mathrm{Ph} . \mathrm{D}$. courses from 2006. He is now the Head of the Research Group on Renewable Electrical Energy Systems at the UPC and Co-Supervisor of the Vestas Power Program in partnership collaboration with the AAU. His recent research interests include power conditioning, integration of distributed energy systems, and control of power converters.

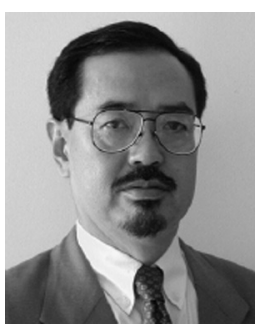

Edson H. Watanabe (S'79-M'81-SM'02) was born in Rio de Janeiro, Brazil, on November 7, 1952. He received the Electronic Engineer and M.Eng. degrees from the Federal University of Rio de Janeiro, Rio de Janeiro, Brazil, in 1975 and 1976, respectively, and the D.Eng. degree from the Tokyo Institute of Technology, Tokyo, Japan, in 1981.

$\mathrm{He}$ became an Associate Professor at COPPE/Federal University of Rio de Janeiro, in 1981, and a Professor in 1993, where he teaches power electronics. His recent research interests include converters analysis, modeling and design, active filters, and FACTS technologies.

Dr. Watanabe is a member of the Institute of Electrical Engineers, Japan, the Brazilian Society for Automatic Control, the Brazilian Power Electronics Society, CIGRE and Power Engineering, Industry Applications and Power Electronics Societies of IEEE. In 2005, he was admitted to the National Order of Scientific Merit, Brazil.

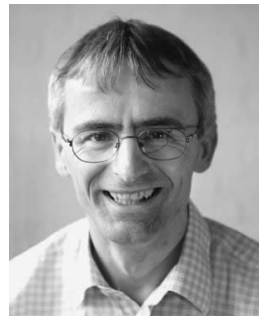

Frede Blaabjerg (S'90-M'91-SM'97-F'03) was born in Erslev, Denmark, on May 6, 1963. He received the M.Sc.EE. and Ph.D. degrees from Aalborg University, Aalborg East, Denmark, in 1987 and 1995, respectively.

He was with ABB-Scandia, Randers, Denmark, from 1987 to 1988. In 2000, he was a Visiting Professor with the University of Padova, Padova, Italy, as well as part-time Programme Research Leader in wind turbines at Research Center Risoe. In 2002, he was a Visiting Professor at the Curtin University of Technology. He is currently a Full Professor in power electronics and drives and Dean of the Faculty of Engineering and Science, Aalborg University. He is involved in more than 15 research projects within the industry including the Danfoss Professor Programme in Power Electronics and Drives. His recent research interests include power electronics, static power converters, ac drives, switched reluctance drives, modeling, characterization of power semiconductor devices and simulation, power quality, wind turbines, and green power inverters. $\mathrm{He}$ is the author or coauthor of more than 350 publications in his research fields including the book Control in Power Electronics (New York: Academic, 2002).

Dr. Blaabjerg received the 1995 Angelos Award for his contribution in modulation technique and control of electric drives, the Annual Teacher Prize from Aalborg University in 1995, the Outstanding Young Power Electronics Engineer Award from the IEEE Power Electronics Society in 1998, five IEEE Prize Paper Awards during the last six years, the C. Y. O'Connor Fellowship from Perth, Australia in 2002, the Statoil-Prize for his contributions in Power Electronics in 2003 , and the Grundfos Prize in acknowledgment of his international scientific research in power electronics in 2004. He is an Associate Editor for the Journal of Power Electronics and for Elteknik. He has been an Associate Editor of the IEEE TRANSACTIONS ON INDUSTRY APPLICATIONS, and currently is Editor-inChief of the IEEE TRANSACTIONS ON POWER ELECTRONICS. He is a member of the European Power Electronics and Drives Association, the IEEE Industry Applications Society Industrial Drives Committee, the Industry Power Converter Committee and the Power Electronics Devices and Components Committee, IEEE Industry Application Society. He has served as member of the Danish Technical Research Council in Denmark from 1997 to 2003 and from 2001 to 2003 he was the Chairman. He has also been the Chairman of the Danish Small Satellite Programme and the Center Contract Committee. He became a member of the Danish Academy of Technical Science, in 2001, and in 2003, he became a member of the Academic Council. From 2002 to 2003, he was a member of the Board of the Danish Research Councils. In 2004, he became Chairman of the Programme Committee on Energy and Environment. 